\title{
Shear Strength Behavior of Different Geosynthetic Reinforced Soil Structure from Direct Shear Test
}

\author{
Danny José Useche Infante ${ }^{1}$ Gonzalo Martin Aiassa Martinez ${ }^{1}$ Pedro Ariel Arrua ${ }^{1}$. \\ Marcelo Eberhardt ${ }^{1}$
}

Received: 18 April 2016/Accepted: 17 May 2016/Published online: 30 May 2016

(C) Springer International Publishing Switzerland 2016

\begin{abstract}
This paper presents the results of direct shear test on soil samples reinforced with geosynthetics, conducted with the aim of characterize the shear strength of reinforced soil composite. Two types of granular soil (well graded sand and silty sand) and four types of geosynthetic (woven and nonwoven geotextile-uniaxial and biaxial geogrid) were selected. Laboratory testing program were performed in two shear boxes, circular box with $63 \mathrm{~mm}$ in diameter and square box with $100 \mathrm{~mm}$ in length; the samples were made with loose and dense sand; the reinforcement layer was placed perpendicular to the failure surface; tests are conducted with three vertical confining pressures: 15.7, 31.4 and $62.8 \mathrm{kPa}$. The effect of different factors that influence the results of the shear tests is analyzed, such as: the particle size of soils, density of soils, shear box size and type of geosynthetics. The test results reveal that the maximum value of shear strength improvement was achieved for dense silty sand samples reinforced with biaxial geogrid. In general, the improvement was more favorable for samples reinforced with geogrid compared to samples reinforced with geotextile.
\end{abstract}

Danny José Useche Infante

djusechei@gmail.com

Gonzalo Martin Aiassa Martinez

gaiassa@scdt.frc.utn.edu.ar

Pedro Ariel Arrua

arruapedro@yahoo.com.ar

Marcelo Eberhardt

meberhardt@civil.frc.utn.edu.ar

1 GIGEF Research Group, Department of Civil Engineering, National Technological University (UTN), Córdoba, Argentina
Keywords Direct shear test - Reinforced sand · Geosynthetics - Shear strength improvement

\section{Introduction}

The interaction between soil and geosynthetic is of utmost importance for the design, modeling and performance of reinforced soil structures. This interaction mechanism depends on the soil properties, reinforcement characteristics and the interrelationship between these materials. Many researches have been carried out to understand the shear strength behaviour of reinforced soil by conducting direct shear tests. The choice of mounting of direct shear test depends on the mechanism of interaction to be reproduced. Palmeira [1] presents test types that characterize, various conditions that can occur in some structures of reinforced soil. Some studies found in the literature, provides laboratory test results with the reinforcement layer positioned parallel to the failure plane induced for the shear box [1-14]. In other research the reinforcing layer is placed perpendicular or rotated to the failure plane [15-20]. In this research, the reinforcement layer was placed perpendicular to the failure plane in order to characterize the behaviour of the composite material when the soil and the reinforcement are sheared.

This paper presents the results of a series of direct shear tests carried out to investigate the factors which control the shear strength of geosynthetic reinforced soil composite for two types of local soil, with two relative densities and four types of geosynthetic. Review of literature shows that the shear behaviour of reinforced soil in direct shear test depends, among other things, on the properties of soil (particle size, density), properties of reinforcement (such as structure and texture) and test conditions (equipment, load application, placement of reinforcement in the soil sample). 


\section{Materials used in the Experiments}

\section{Granular Soil}

Two types of locally available river sand were used as backfill material in this study. By the unified soil classification system (USCS), the soils were classified as well graded sand (SW) and silty sand (SM). The particle size distribution for both soils was characterized using the dry sieving method and the results are shown in Fig. 1. In Table 1 are presented some of the basic properties of the soils. Figure 2 shows the photographs and magnified view for understanding the physical appearance and size variations of these sands. It is observed that the particles are subangular for both sand types and silty sand (SM) contains a greater amount of fine particles.

\section{Geosynthetic Specimens}

Four types of geosynthetic were used in the experimental program: uniaxial geogrid, biaxial geogrid, woven geotextile and nonwoven geotextile. Figure 3 shows the different geosynthetics used as reinforcement in this study. These geosynthetics were provided by CORIPA S.A, a local company. The uniaxial geogrid is made of polyvinyl alcohol (PVA). The biaxial geogrid is fabricated of polypropylene (PP) yarns. The woven geotextile is polypropylene based material. The nonwoven geotextile is polyester based material. In Table 2, the mechanical strength parameters of the four types of geosynthetics used in the tests are shown.

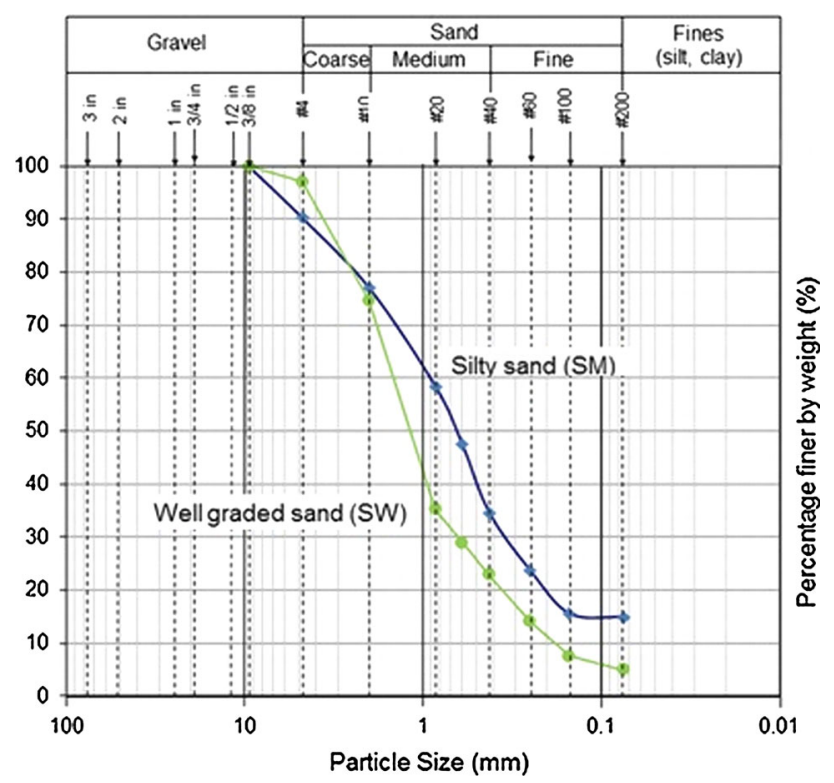

Fig. 1 Grain size distribution curves of soils used
Table 1 Properties of soils

\begin{tabular}{lcc}
\hline Property & \multicolumn{2}{c}{ Type/value } \\
\cline { 2 - 3 } & $\mathrm{SW}$ & $\mathrm{SM}$ \\
\hline Mean grain size, $D_{50}(\mathrm{~mm})$ & 1.28 & 0.66 \\
Size, $D_{30}(\mathrm{~mm})$ & 0.64 & 0.35 \\
Size, $D_{85}(\mathrm{~mm})$ & 3.27 & 3.66 \\
Maximum size, $D_{\max }(\mathrm{mm})$ & 9.53 & 9.53 \\
Maximum dry unit weight $\left(\gamma_{\max }\right)\left(\mathrm{kN} / \mathrm{m}^{3}\right)$ & 17.58 & 18.10 \\
Minimum dry unit weight $\left(\gamma_{\min }\right)\left(\mathrm{kN} / \mathrm{m}^{3}\right)$ & 14.13 & 14.77 \\
Coefficient of uniformity $\left(C_{\mathrm{u}}\right)$ & 8.26 & - \\
Coefficient of curvature $\left(C_{\mathrm{c}}\right)$ & 1.38 & - \\
\hline
\end{tabular}

\section{Testing Methodology}

An experimental program of 120 direct shear tests was conducted. Table 3 presents the factors investigated, which have important effects on the results of direct shear tests, according to the technical literature consulted. Tests are performed with conventional direct shear equipment, where the soil is forced to slide along a horizontal failure plane under a constant rate of displacement, while a constant load is applied normal to the plane of relative movement. The shear box comprises an upper box, fixed in the horizontal directions, and a lower box, without restriction of movement in the horizontal direction. Two types of shear box are used, a circular box with diameter $D=63 \mathrm{~mm}$ and a square box with $L=100 \mathrm{~mm}$ of side in plan.

The ASTMD5321.08 [21] standard suggests that the minimum shear box dimension should be greater than $300 \mathrm{~mm} ; 15$ times the $D_{85}$ of the coarse soil used in the test, or a minimum of 5 times the maximum opening size (in plan) of the tested geosynthetic. In addition, the depth of each shear box should be $50 \mathrm{~mm}$ or six times the maximum particle size of the tested coarse soil, whichever is greater. However, smaller shear boxes could be used if it can be shown that the data generated using smaller devices contains no scale or edge effects when compared to the above-mentioned minimum size devices. Various studies have shown that the size of the sample does not affect significantly the friction parameters obtained in the test $[2,11,15,18]$, these works recommend that a ratio between mean particle size to length of the box must be in the range of 50-300.

The geosynthetic specimens were positioned perpendicular to the failure plane (see Fig. 4) in order to determine the behaviour of soil-geosynthetic system when the shear force acts normal to the reinforcing layer. Athanasopoulos [16] and Bauer and Zhao [17] consider this type of testing at most appropriate to represent the field conditions. The test method used in this study differs from both 
Fig. 2 Microscopic view of sands

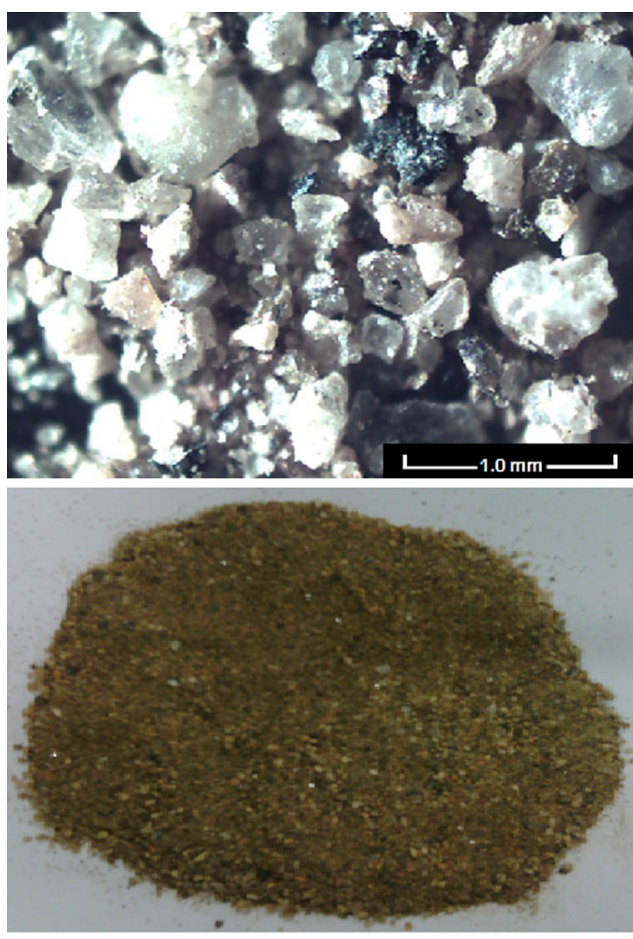

(a) Well graded sand (SW)

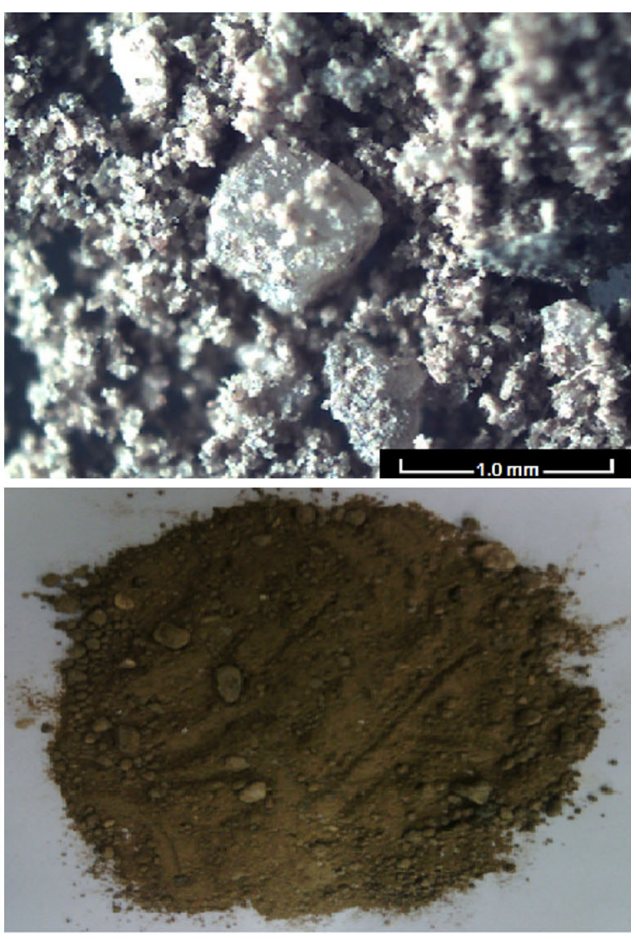

(b) Silty sand (SM) the direct shear test and the pull-out test which are presently used for evaluating soil-geosynthetic interaction. These test methods have basic differences in the boundary conditions, stress paths and failure mechanisms imposed to the specimen. A complete review on the advantages and limitations of these tests is presented by Palmeira [1]. A perpendicular direction of the reinforcement was chosen in order to facilitate its installation in the shear box, however, it is know that it does not represent the optimum orientation for obtain the maximum reinforcement effect in the soil mass. Some reports suggest values for the optimal orientation of reinforcement in the soil sample [15, 17, 18, 20].

For the direct shear test, the samples were prepared at the relative densities of 10 and $90 \%$. The geosynthetic specimens were positioned vertically along a center-line on a shear box with the longitudinal fibers perpendicular to the failure plane (Fig. 5a). Subsequently, the shear box was filled with the sand. The sand was placed inside the shear box by raining method to achieve the desired relative density of $10 \%$ for loose samples. For dense samples the sand were compacted to a relative density of $90 \%$ by tamping. The preparation of some samples is illustrated in Fig. 5a, it is observed that the lateral earth pressure maintains the verticality of the geosynthetic at the beginning of the trial. Figure $5 \mathrm{~b}$ shows some failed specimens, it can be seen the deformation in the geosynthetic caused by placement of reinforcement perpendicular to the shearing plane.
The direct shear tests were conducted using three different normal stresses of $15.7,31.4$ and $62.8 \mathrm{kPa}$. All the tests involved applying the normal stress and monitoring the vertical displacement. Shear test was performed with a displacement speed of $1 \mathrm{~mm} / \mathrm{min}$ at the time of loading shear load, and vertical load was controlled, to be maintained at a constant level. Values of shear force, horizontal displacement and vertical displacement of the top cap of the sample were recorded at regular intervals during shearing. Data were acquired using a DTF Datalogger where they are passed directly to the computer for processing. Direct shear apparatus is shown in Fig. 6.

\section{Results and Discussion}

To evaluate the frictional behavior of geosynthetic reinforced soil composite, shear stress-horizontal displacement and vertical displacement-horizontal displacement curves are performed. Horizontal displacement is defined as a percentage of the quotient of shear displacement divided by the length of shear box. For the circular box the length was taken as the diameter, $D=63 \mathrm{~mm}$, while for the square box, the length is equal to the equivalent diameter. This corresponds to the diameter of a circular area that is equal to the square area of the box $\left(100 \times 100 \mathrm{~mm}^{2}\right)$ and is calculated as follows: 
Fig. 3 Different geosynthetics used in the tests (dimensions in $\mathrm{mm}$ )
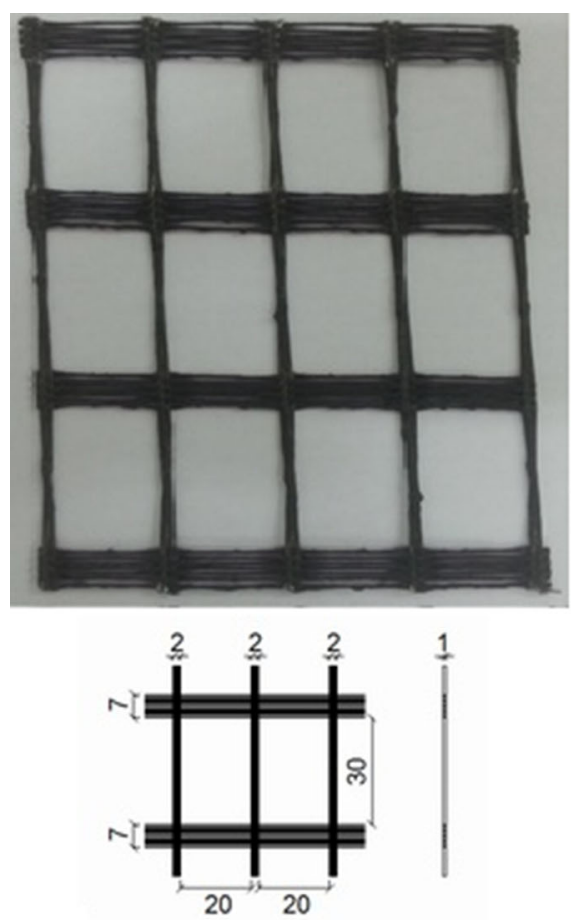

(a) Uniaxial geogrid

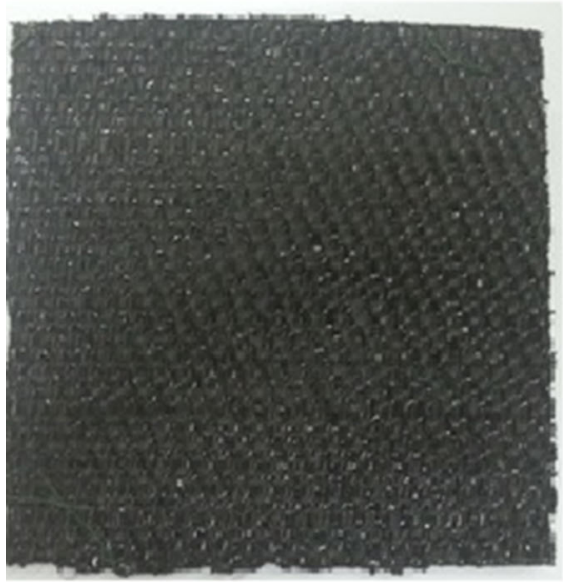

(c) Woven geotextile
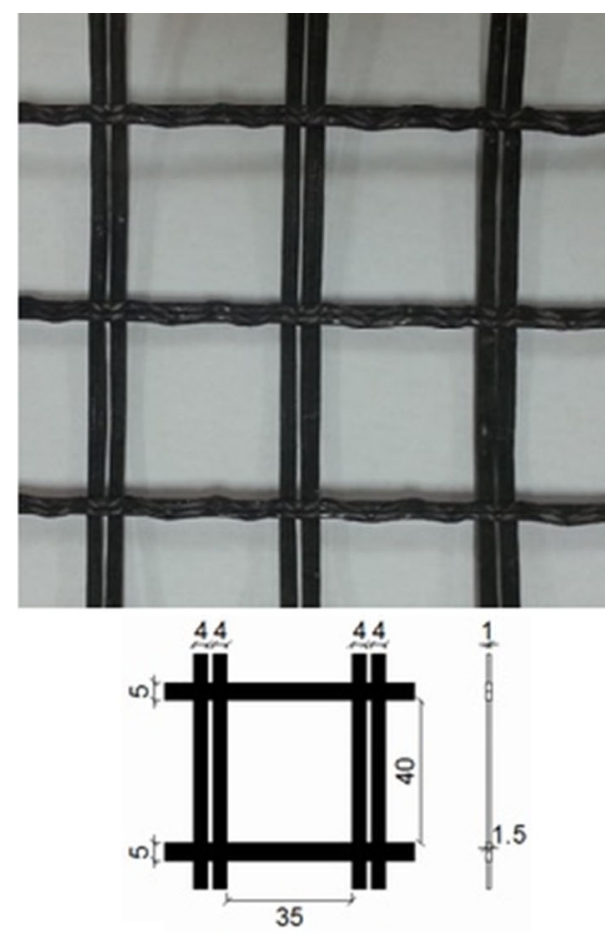

(b) Uniaxial geogrid

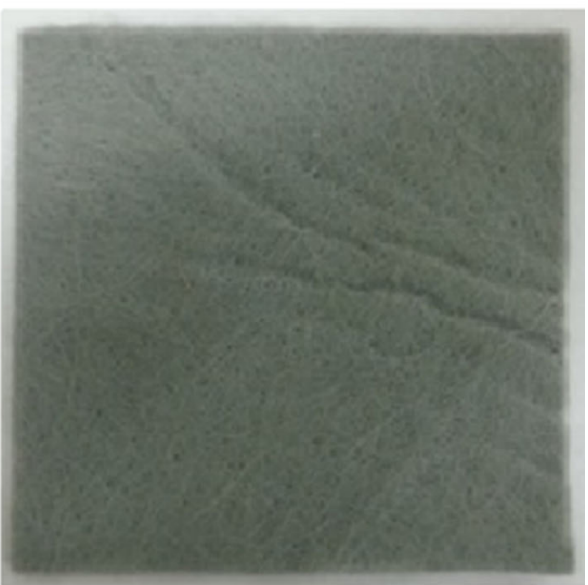

(d) Nonwoven geotextile
$D_{\text {equ }}=\frac{2 B}{\sqrt{\pi}}$,

where $D_{\text {equ }}$ is the equivalent diameter and B is the width of the square box $(100 \mathrm{~mm})$. The equivalent diameter in this case was $D_{\text {equ }}=112.84 \mathrm{~mm}$. The test results are discussed in following subsections.

\section{Shear Stress Versus Horizontal Displacement}

Shear stress versus horizontal displacement curves for all samples tested were performed. The curves of the samples with soil type (SW) without reinforcement and reinforced with the four types of geosynthetic, for loose and dense samples, in circular shear box, are shown in Fig. $7 \mathrm{a}$, b respectively. It is observed different behaviour for the loose and dense sand. As we can see from Fig. 7a, for the loose sand, shear stress shows a gradual increase to the maximum value at a certain strain value at which the curve reaches an asymptotic behaviour, while for the dense sand (see Fig. 7b) stress increases to a peak with increasing shear strain from zero to a certain magnitude and thereafter, it decreases gradually to the residual shear stress with the increase of the strain. Peak shear stress occurs for strain between 5 and $8 \%$ for loose sands and strain between 3 and $5 \%$ for dense sands. 
Table 2 Mechanical properties of geosynthetics (provided from the suppliers technical brochures)

\begin{tabular}{|c|c|c|c|c|}
\hline \multirow[t]{2}{*}{ Property } & \multicolumn{4}{|l|}{ Reinforcement } \\
\hline & Uniaxial & Biaxial & Woven & Nonwoven \\
\hline Type of geosynthetic material & Uniaxial Geogrid & Biaxial geogrid & Woven geotextile & Nonwoven geotextile \\
\hline Type of polymer & Polyvinyl (PVA) & Polypropylene (PP) & Polypropylene (PP) & Polyester (PET) \\
\hline Nominal mass per unit area $\left(\mathrm{g} / \mathrm{m}^{2}\right)$ & 240 & 200 & 386 & 250 \\
\hline \multicolumn{5}{|l|}{ Modulus to def. $5 \%(\mathrm{kN} / \mathrm{m})$} \\
\hline $\mathrm{LD}^{\mathrm{a}}$ & 630 & $\geq 360$ & - & - \\
\hline $\mathrm{CD}^{\mathrm{b}}$ & - & $\geq 360$ & - & - \\
\hline \multicolumn{5}{|l|}{ Modulus to def. $2 \%(\mathrm{kN} / \mathrm{m})$} \\
\hline $\mathrm{LD}^{\mathrm{a}}$ & 700 & $\geq 400$ & - & - \\
\hline $\mathrm{CD}^{\mathrm{b}}$ & - & $\geq 400$ & - & - \\
\hline \multicolumn{5}{|l|}{ Mesh opening (mm) } \\
\hline $\mathrm{LD}^{\mathrm{a}}$ & 20 & 40 & - & - \\
\hline $\mathrm{CD}^{\mathrm{b}}$ & 30 & 40 & - & - \\
\hline \multicolumn{5}{|l|}{ Thickness (mm) } \\
\hline $\mathrm{LD}^{\mathrm{a}}$ & 1.0 & 1.5 & 1.0 & 1.2 \\
\hline $\mathrm{CD}^{\mathrm{b}}$ & 1.0 & 1 & 1.0 & 1.2 \\
\hline
\end{tabular}

${ }^{a}$ Longitudinal direction

b Cross machine direction

Table 3 Tests conducted

\begin{tabular}{lll}
\hline No. & Effect to be investigated & Variables \\
\hline 1 & Soil particle size & SW with $D_{50}=1.32 \mathrm{~mm}$ \\
& SM with $D_{50}=0.66 \mathrm{~mm}$
\end{tabular}

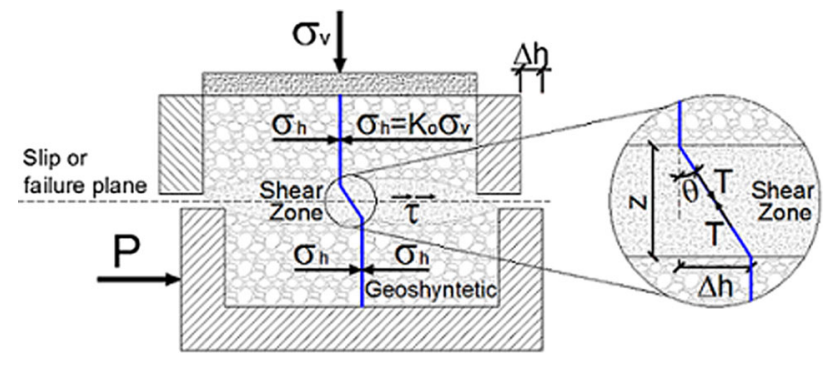

Fig. 4 Scheme of direct shear test performed (modified from Athanasopoulos [16])

Shear stress versus horizontal displacement behaviour for soil type (SM) is similar to that shown for the samples with soil type (SW) as we can see in Fig. 8. On the other hand, the shear stress increases as the confining pressure increased, Fig. 9a and $\mathrm{b}$ show the shear stress versus horizontal displacement curves for samples reinforced with woven geotextile, for soil type (SW), with two relative densities and prepared in two shear box type. As shown in the figure, the samples prepared in the square box $(L=100 \mathrm{~mm})$, showed higher values of shear stress compared with samples in circular box $(D=64 \mathrm{~mm})$. The peak value of shear stress occurs to minor deformations in circular box that the square box. This behaviour can occur for the border effect, which is higher in the smaller box (circular box). To include a geosynthetic layer in soil samples, the shear stress was significantly increased (see Figs. 7, 8).

\section{Vertical Displacement Versus Horizontal Displacement}

Vertical displacement versus horizontal displacement curves were performed in order to verify the change in the 


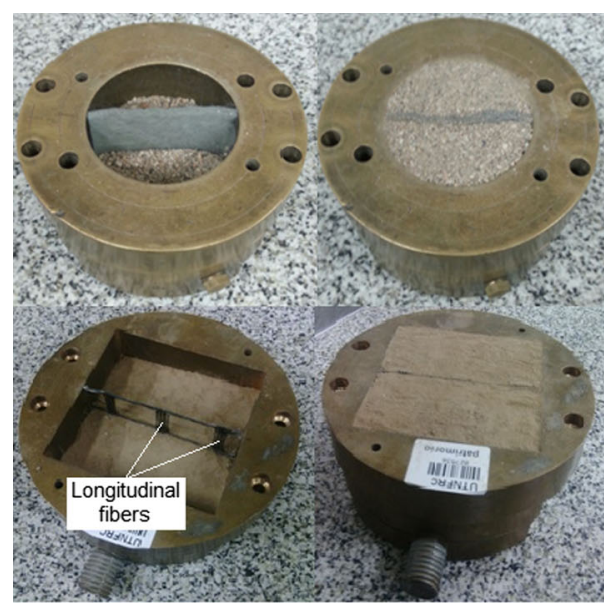

(a) Placement of sand and geosynthetics

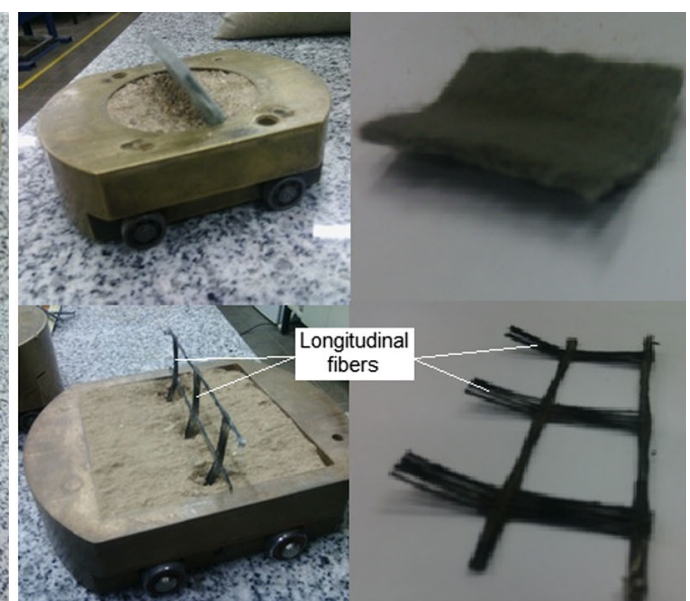

(b) Failed specimens

Fig. 5 Sample preparation and failed specimens for samples reinforced with nonwoven geotextile (above) and uniaxial geogrid (down)

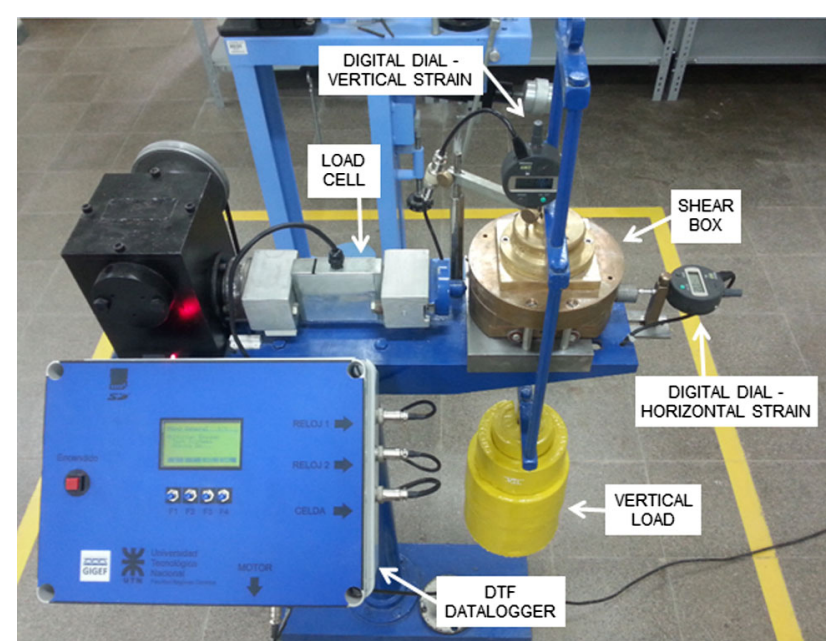

Fig. 6 Direct shear apparatus

sample volume as the direct shear test progresses. In dense samples, a dilatant behaviour is exhibited as shown in Figs. $7 \mathrm{~d}$ and $8 \mathrm{~d}$. An expansion occurs until the peak shear stress occurs, after which, the soil contracts to a value of constant volume and a residual shear stress. The change of expansion to compression occurs around of 2, 3 and $5 \%$ of horizontal displacement for $15.7,31.4$ and $62.8 \mathrm{kPa}$ of vertical confining pressure respectively. For loose sand samples, the sample volume decreases as the shear stress increases to the maximum value where reached a constant value (see Figs. 7c, 8c). According to the vertical displacement vs. horizontal displacement curves, the type of geosynthetic had no significant effect on the volume change of the sample, the expansion or compression of the samples is determined by the density of the sample.

\section{Failure Envelope}

It can be assumed that the shear strength of geosynthetic reinforced soil composites follows an elastic-plastic (or rigid-plastic) model and the Coulomb failure criterion analogously to the behaviour of soil shear strength [22, 23]. The shear stress at the geosynthetic reinforced soil composites can be calculated as follows:

$\tau=C_{\mathrm{a}}+\sigma_{\mathrm{v}} \tan \delta$,

where $\tau$ is the shear stress of geosynthetic reinforced soil, $C_{\mathrm{a}}$ is the apparent cohesion, $\sigma_{\mathrm{v}}$ is the normal stress and $\delta$ is the friction angle of geosynthetic reinforced soil.

In this paper, linear failure envelopes were performed using the values of peak shear stress (loose sand) and peak and residual shear stress (dense sands). Shear stresses obtained for the three normal stresses used $(15.7,31.4$ and $62.8 \mathrm{kPa}$ ) are plotted. Failure envelopes were made by calculating the linear trend of the data for all samples. In Fig. 10, lineal failure envelopes are presented grouped by type and relative density of the soil. The comparison of different envelopes shows the effect of inclusion of geosynthetic elements in the soil mass, an apparent cohesion occurs in reinforced soil samples. Better results for shear stress in sand well graded (SW), loose and dense, are obtained for the samples reinforced with woven geotextile. For silty sand (SM) loose, higher shear stress values are given with the inclusion of biaxial geogrid, for samples with silty sand (SM) dense, best results of peak and residual shear stresses are obtained with the samples reinforced with woven geotextile and biaxial geogrid respectively.

A lineal regression to estimate the soil friction angle and the apparent cohesion of geosynthetic reinforced soil composites was performed. In Table 4, peak friction angles of 


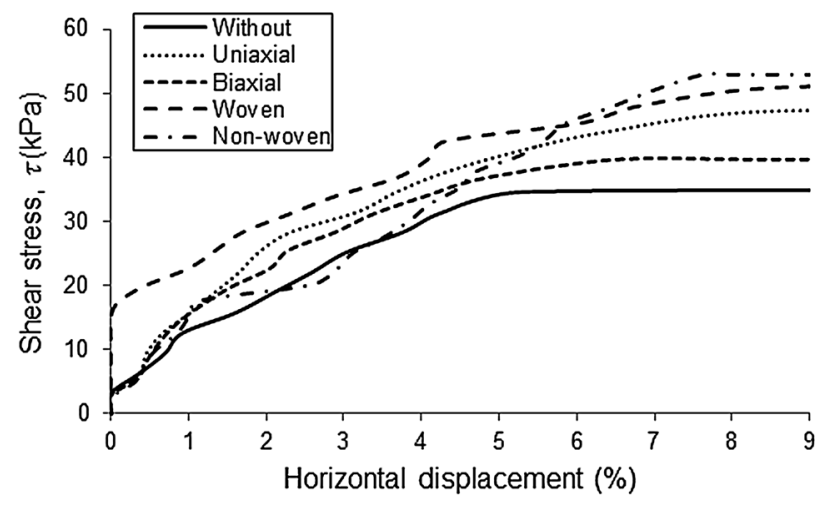

(a) Shear stress vs. horizontal displacement, $D \mathrm{r}=10 \%$

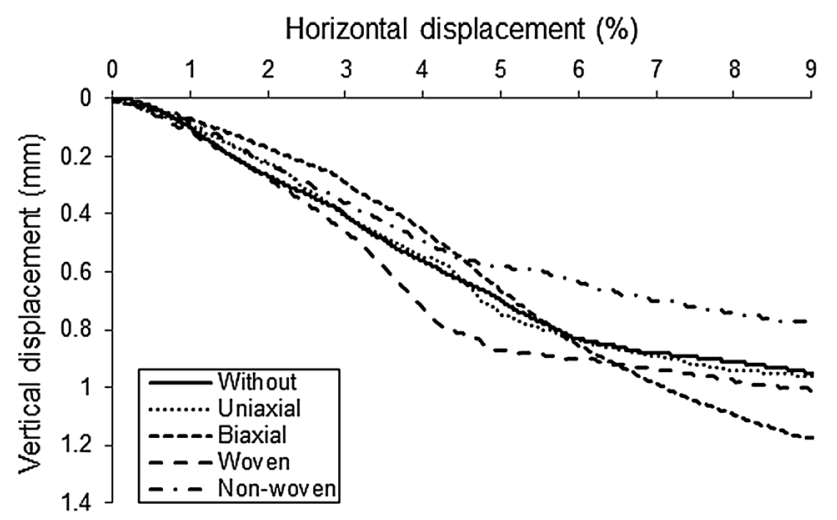

(c) Vertical displacement vs. horizontal displacement Dr $=10 \%$

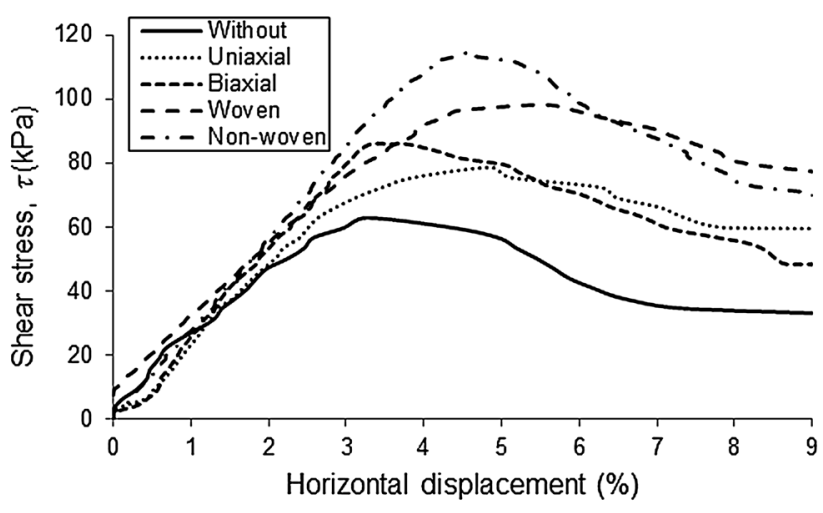

(b) Shear stress vs. horizontal displacement, $D \mathrm{r}=90 \%$ Horizontal displacement (\%)

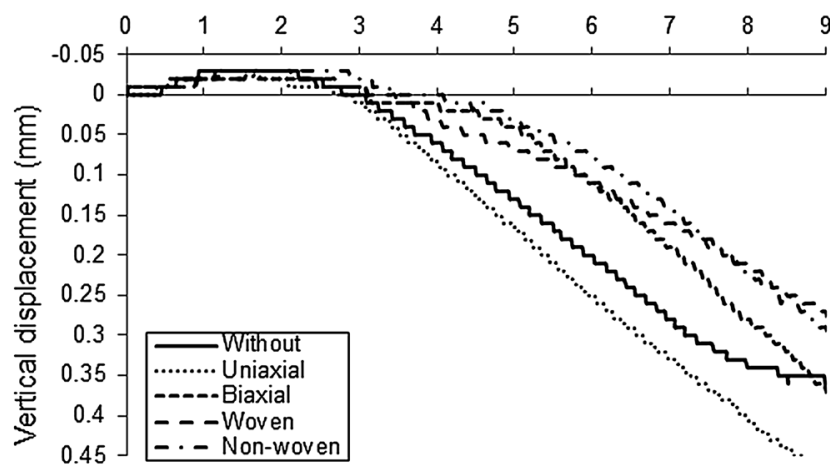

(d) Vertical displacement vs. horizontal displacement $D_{1}=90 \%$

Fig. 7 Shear behaviour for well graded sand (SW), for normal stress of $31.4 \mathrm{kPa}$, without reinforced and reinforced soil (circular box)

interface for all samples tested are shown. Most of the reinforced soil exhibited better performance compared to unreinforced soil; friction angles of reinforced sand were greater, indicating an improvement in the shear strength of the soil. No significant difference in the soil friction angle between two types of boxes are found, the variation in friction angle was less than $3.3 \%$, the angle was slightly lower in the samples prepared in the square box $\left(100 \times 100 \mathrm{~mm}^{2}\right)$. It has been found that the friction angle and angle of repose are somewhat correlated [13, 24, 25]. The average angle of repose for the two types of soil used in this experimental program was estimated in accordance with the procedures given in ASTM C1444 [26]. Figure 11 presents angles of repose for well graded sand (SW) and silty sand (SM). It was observed that the measured values are close to friction angle of loose samples without reinforcement obtained in direct shear tests (see Table 4; Fig. 10). Therefore, the angle of repose measured for the soil validates the results of direct shear tests for samples with unreinforced loose sand. Residual friction angles for dense samples are presented in Table 5; variation in residual friction angle for the two types of shear box was less than $1.5 \%$. Apparent cohesion values for peak shear stress and residual shear stress are shown in Tables 4 and 5; apparent cohesion was greater in the case of square shear box for most samples in the two soil types and for both densities.

\section{Shear Strength Improvement}

In this study, shear strength improvement index will be used to estimate the improvement in shear strength of the soil to include geosynthetic. This index is defined as the ratio of the shear strength at the geosynthetic reinforced soil composites to the shear strength of the soil at the same overburden condition. Similar relationships have been identified in the literature as the "Interface Efficiency" [2, 5]. Shear strength improvement for cohesive soil is defined as:

$C_{\mathrm{i}}=\frac{C_{\mathrm{a}}+\sigma_{\mathrm{v}} \tan \delta_{\mathrm{a}}}{C+\sigma_{\mathrm{v}} \tan \phi}$,

And for granular soils:

$C_{\mathrm{i}}=\frac{\tan \delta_{\mathrm{a}}}{\tan \phi}$, 


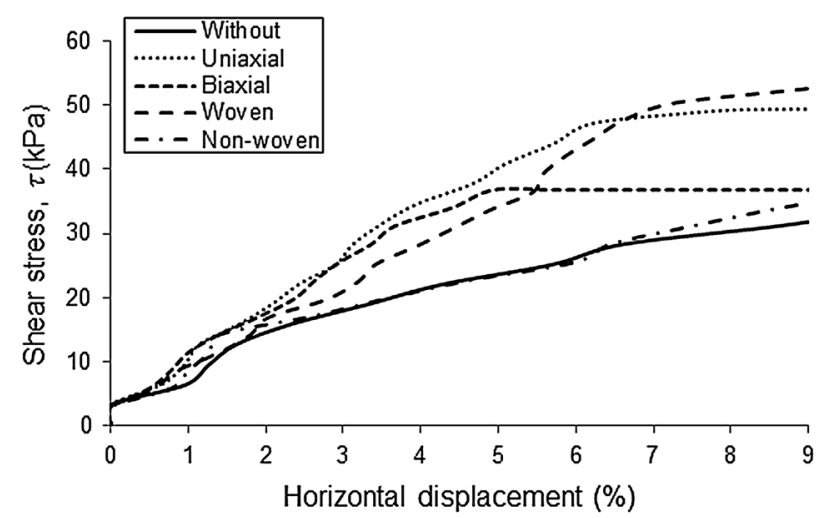

(a) Shear stress vs. horizontal displacement, $\mathrm{Dr}=10 \%$

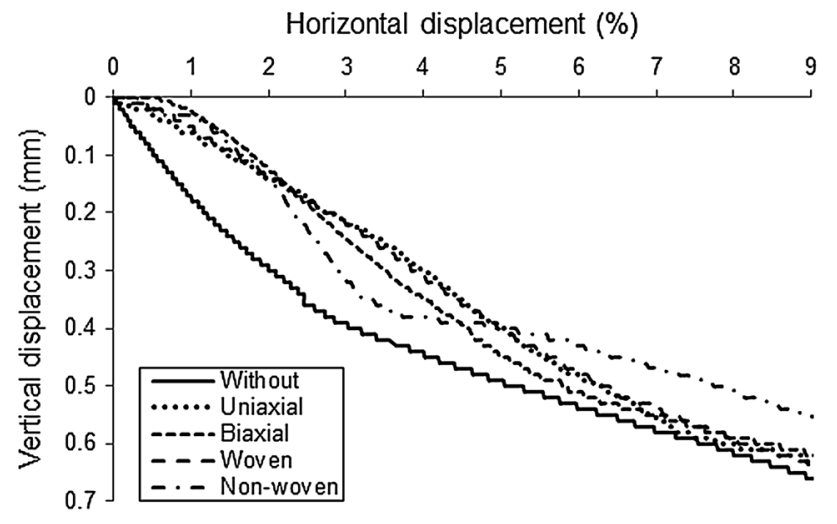

(c) Vertical displacement vs. horizontal displacement $D_{1}=10 \%$

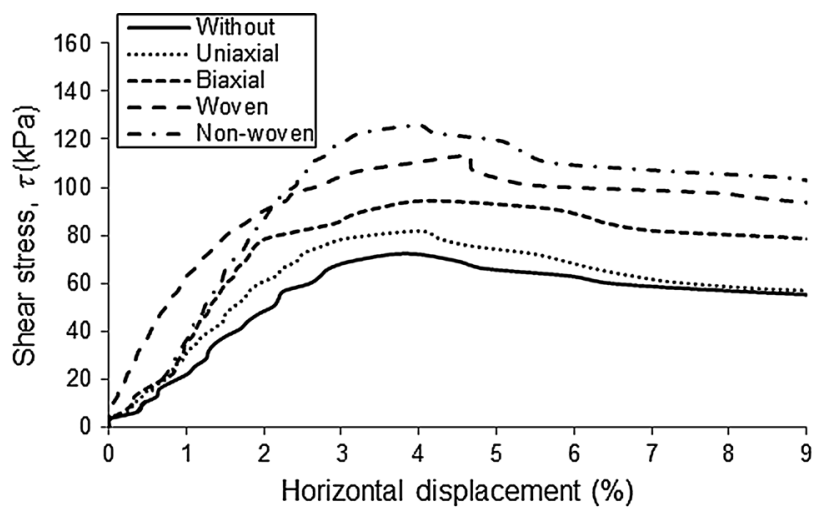

(b) Shear stress vs. horizontal displacement, $D \mathrm{r}=90 \%$

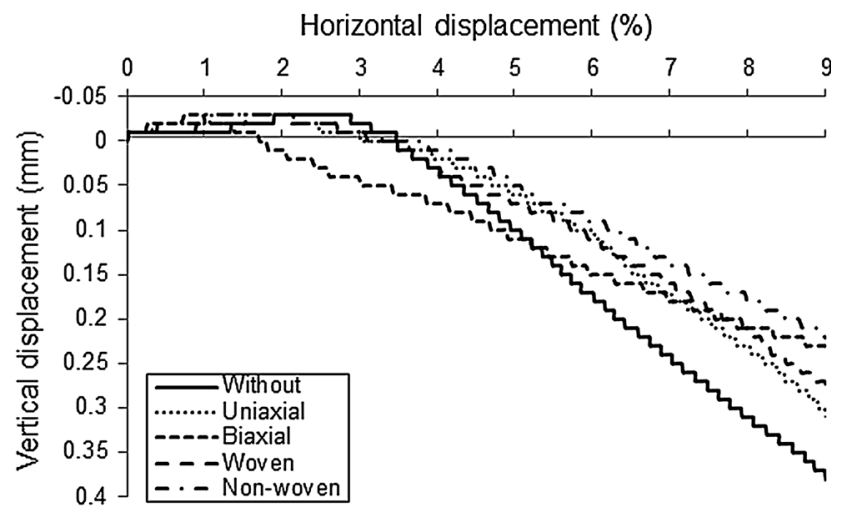

(d) Vertical displacement vs. horizontal displacement $\mathrm{Dr}=90 \%$

Fig. 8 Shear behaviour for silty sand (SM), for normal stress of $31.4 \mathrm{kPa}$, without reinforced and reinforced soil (circular box)

where $C_{\mathrm{i}}$ is the shear strength improvement, $C_{\mathrm{a}}$ is the apparent cohesion of reinforced soil, $C$ is the cohesion of soil without reinforcement, $\sigma_{\mathrm{v}}$ is the normal stress, $\delta_{\mathrm{a}}$ is the friction angle of geosynthetic reinforced soil composites and $\phi$ is the friction angle of soil without reinforcement. Most of the reinforced soil samples exhibit apparent cohesion, so that the Eq. 3 is used to calculate the shear strength improvement of the geosynthetic reinforced soil composites, the results for peak and residual shear stress are presented in Tables 6 and 7 respectively. The shear strength improvement of the reinforced sand ranged from 1.03 to 2.21 depending on the type of geosynthetic and vertical stress. Shear strength improvement values showed smaller differences between both shear boxes for higher values of vertical stress.

\section{Apparent Friction Angle at Soil-Geosynthetic Interface}

Alternative way of calculating the improvement in the soil when geosynthetic elements are included is to calculate the apparent friction angle of soil-geosynthetic interface rather than estimate it by linear regression of failure envelopes. To calculate the apparent friction angle was used the model presented by Hataf and Rahimi [27] for fiber reinforced soil and the model developed for Athanasopoulos [16], which are presented below. The underlying assumptions in the derivation of the mathematical equations of the model are as follows:

- During direct shear testing the thickness of the shear zone, $\mathrm{z}$, remains constant.

- The sand mass outside the shear zone remains in the atrest condition.

From the second assumption it follows that the normal stress, $\sigma_{\mathrm{h}}$, acting on the sand-geotextile interface will be

$\sigma_{\mathrm{h}}=K_{\mathrm{o}} \sigma_{\mathrm{v}}$,

where $K_{\mathrm{o}}$ is the coefficiency of earth pressure at rest $=1-\sin \phi$, and $\sigma_{\mathrm{v}}$ is the vertical confining pressure. The value of tensile force, $T$, developed in the sheet of reinforcement will be, 


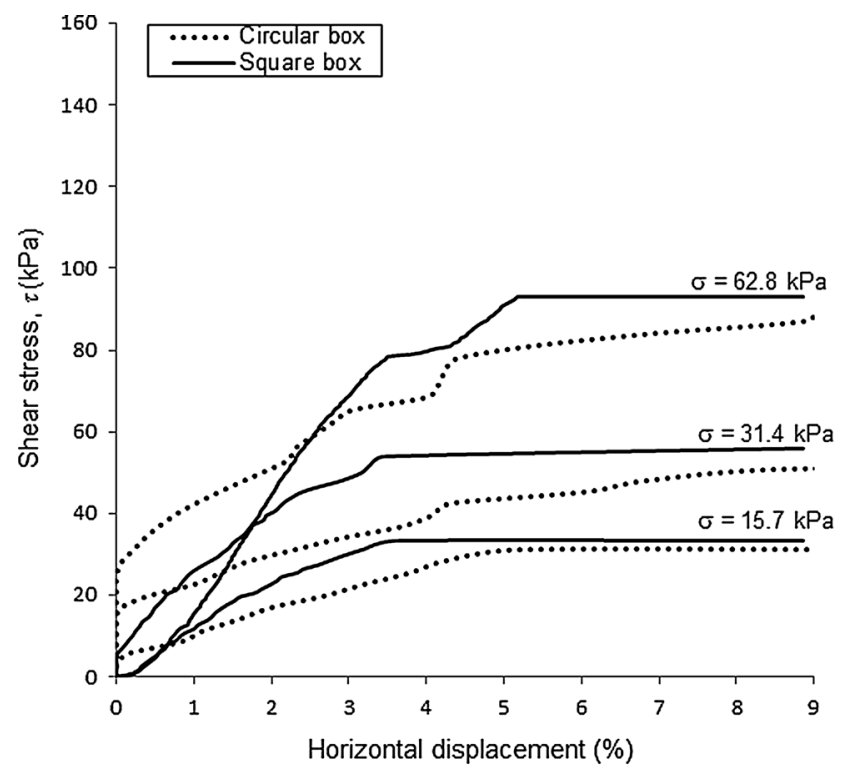

(a) Shear stress vs. horizontal displacement, $\mathrm{Dl}=10 \%$

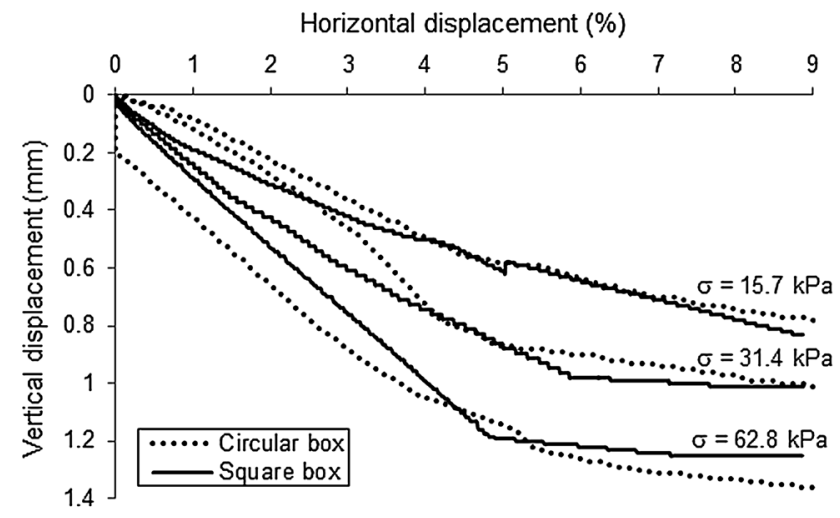

(c) Vertical displacement vs. horizontal displacement $\mathrm{Dr}=10 \%$

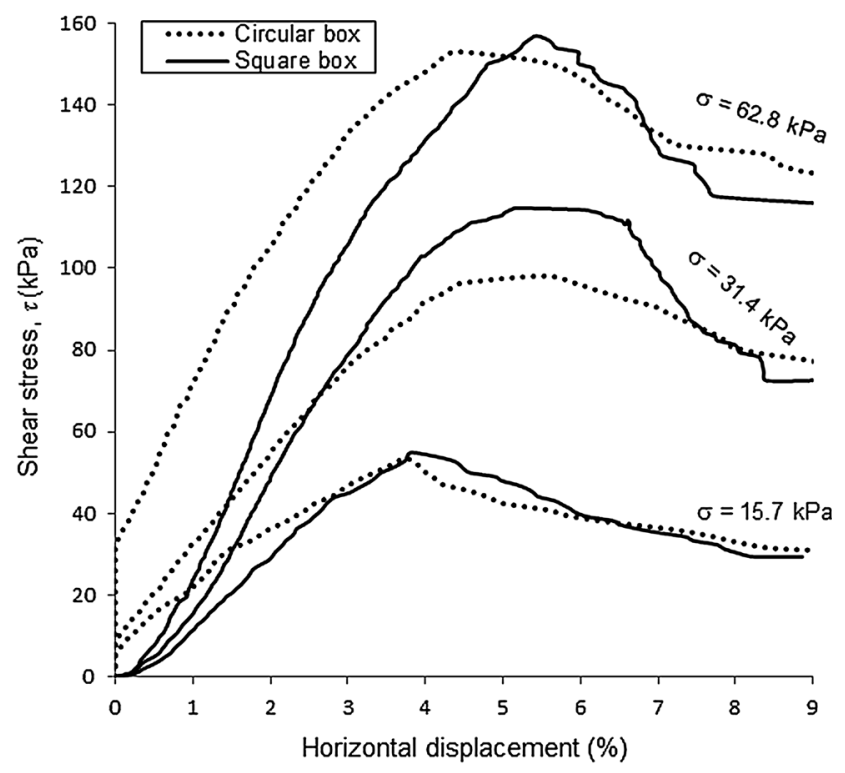

(b) Shear stress vs. horizontal displacement, $\mathrm{Dr}=90 \%$

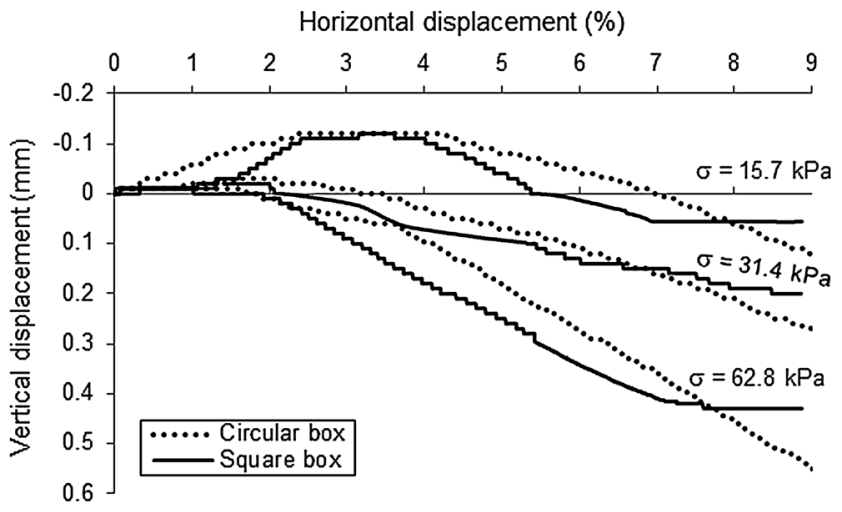

(d) Vertical displacement vs. horizontal displacement Dr $=90 \%$

Fig. 9 Shear behaviour for well graded sand (SW) reinforced with woven geotextile, for normal stresses of 15.7, 31.4 and $62.8 \mathrm{kPa}$, for circular and square shear box

$T=A_{\mathrm{s}} K_{\mathrm{o}} \sigma_{\mathrm{v}} \tan \delta$

where $A_{\mathrm{s}}$ is the area of sand-geotextile contact surface, and $\delta$ is the apparent friction angle at the interface. The shear strength increase, $\Delta t$, of reinforced sand will be as follows (Hataf and Rahimi [27]):

$\Delta \tau=\frac{T}{A_{\mathrm{f}}}(\sin \theta+\cos \theta \tan \phi)$

where $\Delta \tau$ is the difference of peak strength between reinforced and unreinforced sand, $A_{\mathrm{f}}$ is the sheared area of sand in the direct shear test, $\theta$ is the angle defined in Fig. 4, and $\phi$ is the angle of internal friction of soil.

The value of angle $\theta$, according to Fig. 4, depends on the shear displacement at peak strength, $\Delta h_{\text {peak }}$, and the thickness of shear zone, $z$. In this study, an average value of $z$ was obtained by conducting direct shear tests, in the two types of soil (SW and SM); reinforced with a sheet of thin, smooth aluminium foil. A visual examination of the reinforcement sheet after testing revealed that a strip along the centre-line of the sheet was characterized by a rough surface. The width of this roughened strip was taken to be equal to the thickness of the shear zone, $z$. Thus, the average value of shear zone thickness was, $z=5 \mathrm{~mm}$ for both shear box and two types of soil. Then, the angle $\theta$ is calculated as:

$\theta=\tan ^{1}\left(\frac{\Delta h}{z}\right)$

by combining Eqs. (6) and (7) the value of $\delta$ can be obtained as follows: 


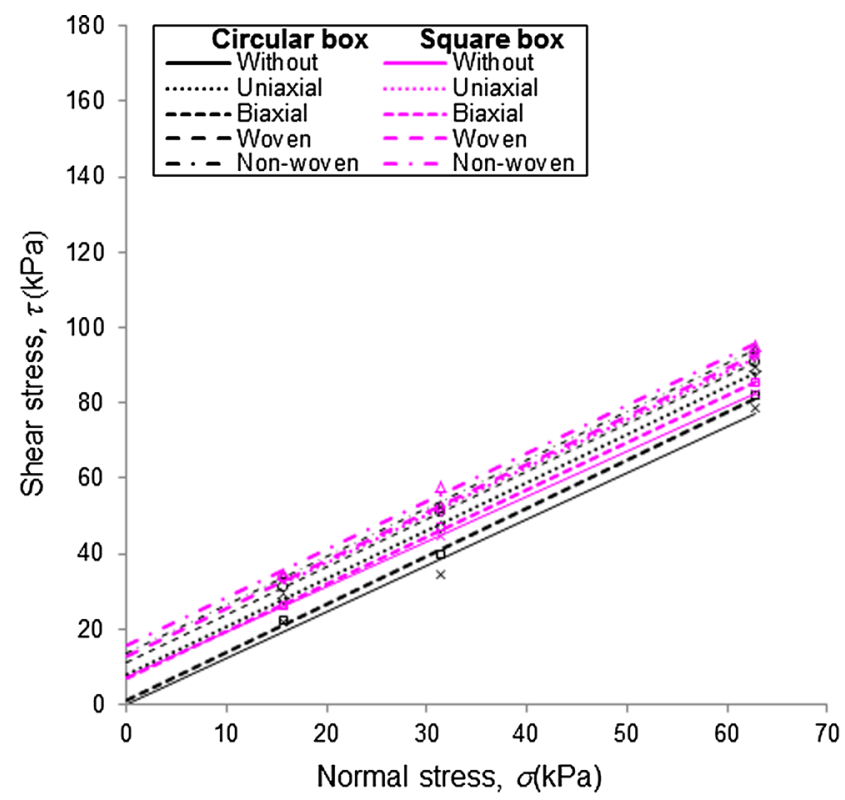

(a) Well graded sand (SW), $D 1=10 \%$, peak shear stress

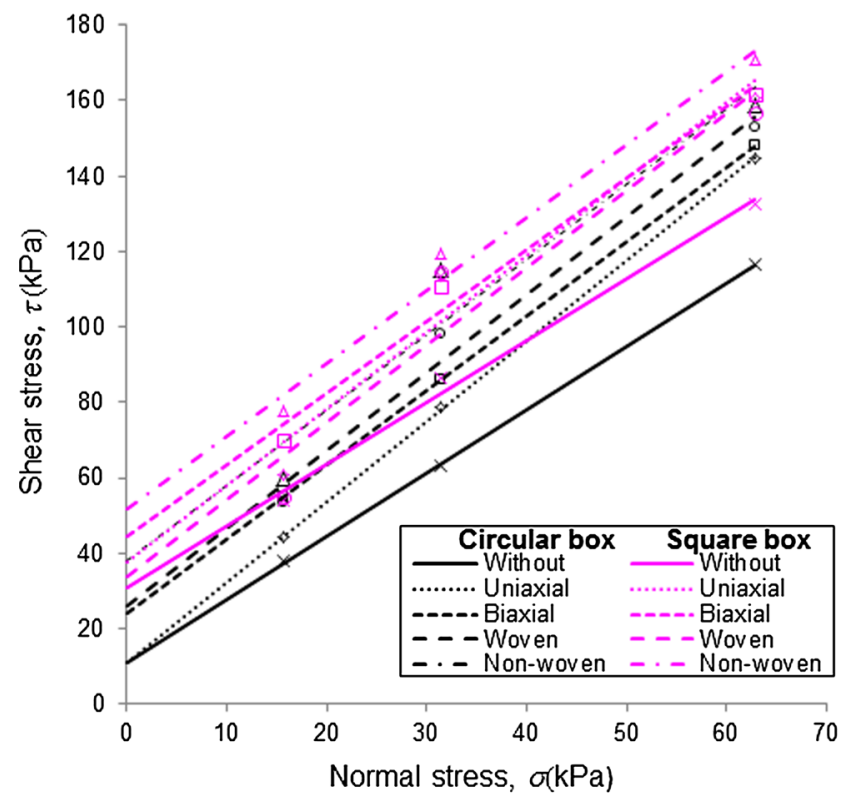

(c) Well graded sand (SW), $D \mathbf{r}=90 \%$, peak shear stress

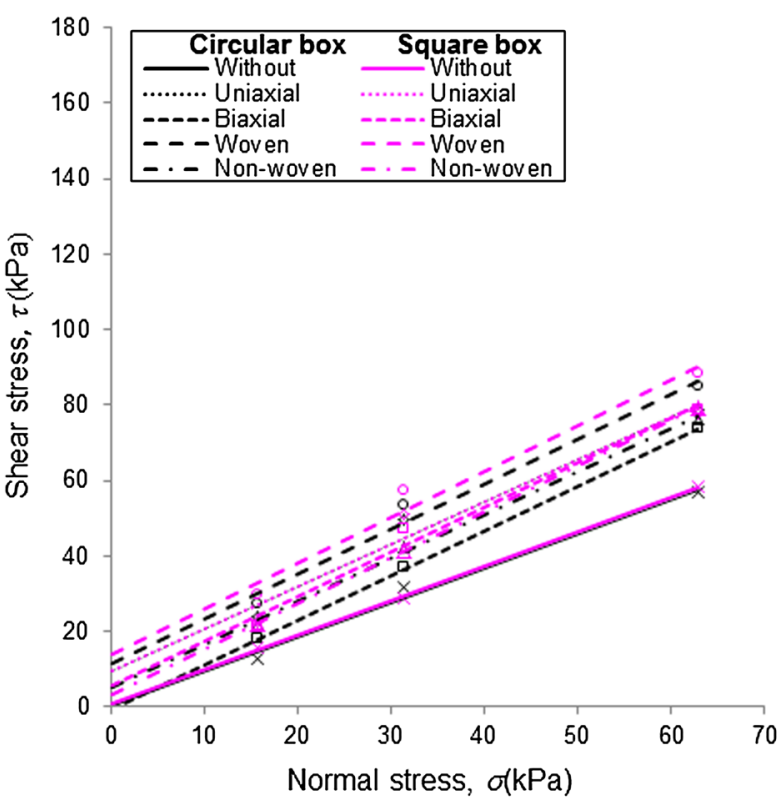

(b) Silty sand (SM), $D 1=10 \%$, peak shear stress

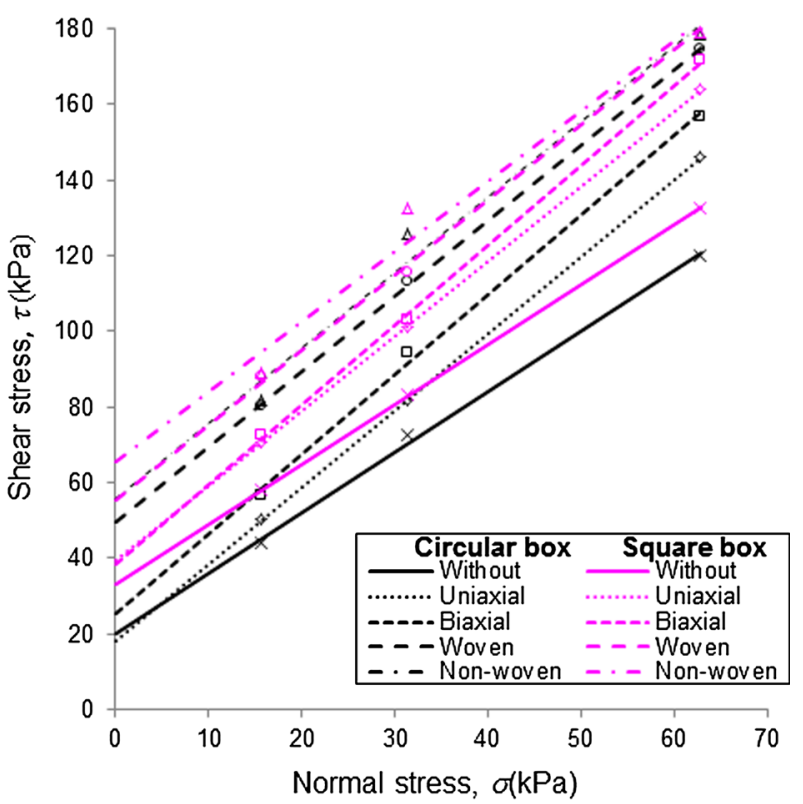

(d) Silty sand (SM), $\mathrm{Dr}=90 \%$, peak shear stress

Fig. 10 Comparison of the failure envelopes for unreinforced and reinforced sand

$\delta=\tan ^{1}\left[\left(\frac{A_{\mathrm{f}}}{A_{\mathrm{s}}}\right) *\left(\frac{\Delta \tau}{\sigma_{\mathrm{v}}}\right) *\left(\frac{1}{(\sin \theta+\cos \theta \tan \phi)(1-\sin \phi)}\right)\right]$,

where $\Delta \tau$ is estimated from the results of tests. The values of $\delta$ for all specimens tested were calculated and then the average value was estimated for three vertical confining pressure values.
The values of apparent interface friction angle in the normalized form, $\delta / \phi$, are shown in Table 8 for peak shear stress, and are shown in Table 9 for residual shear stress in dense soil. It is noteworthy that for the samples in both shear boxes, uniaxial geogrid has the lowest improvement in relation to the other inclusions. As shown in Table 8, samples with silty sand (SM) had a more favorable shear behaviour compared to samples with well graded sand (SW) for peak shear stress. 


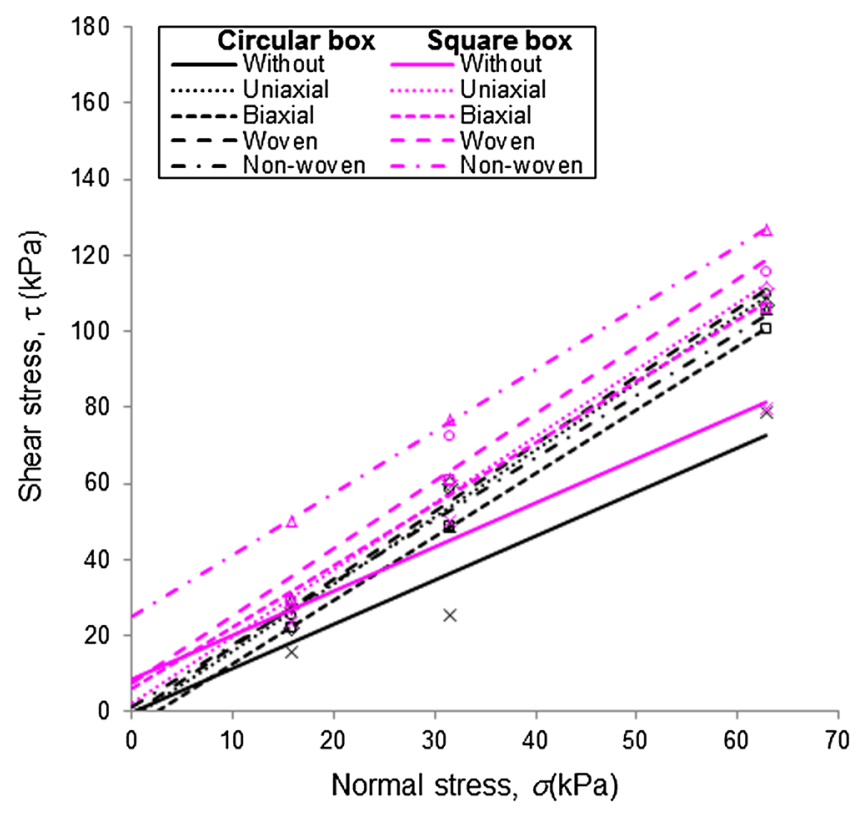

(e) Well graded sand (SW), $D r=90 \%$, residual shear stress

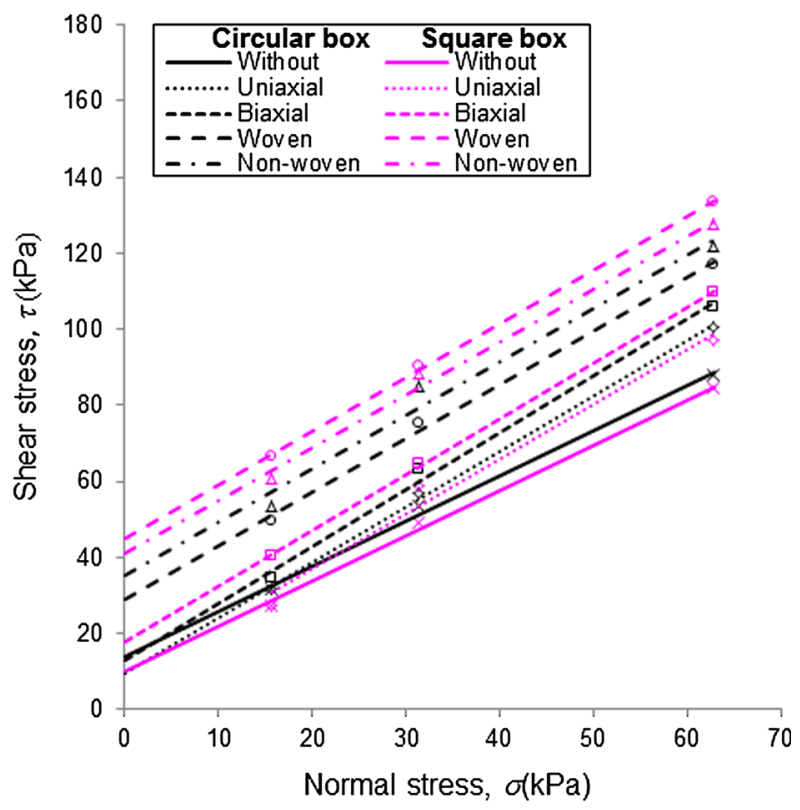

(f) Silty sand (SM), $D \mathbf{r}=90 \%$, residual shear stress

Fig. 10 continued

\section{Effect of Different Parameters in Shear Strength Behaviour of Geosynthetic Reinforced Soil Composite}

\section{Particle Size}

It can be seen in Tables 6 and 7, in samples with silty sands (SM), with average size $D_{50}=0.66 \mathrm{~mm}$, more optimal improvement in the peak shear strength was obtained in comparison with samples with well graded sand (SW) with $D_{50}=1.32 \mathrm{~mm}$. That is, on the soil with lower average particle size and larger amount of fines, higher improvement was obtained in the frictional behaviour of the reinforced soil; these results are similar with that reported by Athanasopoulos [16] and Liu et al. [6]. From the data in Table 4, the peak friction angles of reinforced soils with greater average particle size (sand $\mathrm{SW}, D_{50}=1.32 \mathrm{~mm}$ ) were higher than the samples with lower average particle size (silty sand SM $D_{50}=0.66 \mathrm{~mm}$ ), although the improvement in the shear strength of the soil-geosynthetic interface was greater in soils with lower average particle size.

\section{Density of Samples}

Regardless of soil type or size of the shear box, loose samples always showed a distinct behaviour, characterized by an increase in shear stress with increasing the horizontal displacement up to a peak shear stress value. Dense samples $(\mathrm{Dr}=90 \%)$ also show a typical behaviour; the shear stress increases to a peak with increasing horizontal displacement from zero to a certain magnitude and thereafter, it decreases gradually to the residual shear stress with the increase of the horizontal displacement (see Figs. 7a-b, $8 \mathrm{a}-\mathrm{b})$. The reason for this correspondence is that there is a considerable degree of interlocking on dense soil and there is an additional friction on the interface between soil and reinforcement. The behaviour exhibited by the samples tested corresponds to the typical behaviour reported in technical literature for direct shear tests on reinforced granular soils $[5,10,16]$.

Dilatancy effect, typical of the behaviour of dense sand samples is clearly seen in Figs. $7 d$ and $8 d$, an initial expansion occurs in the sample volume, followed by a contraction up to a constant volume when the residual shear stress is reached. The initial expansion in the volume of the sample occurs because the particles are so interlocked with each other in the dense sand, when the shear force is applied to a rearrangement of these particles occurs and the volume increases. After reaching the peak shear stress, the particles rearranged and the sample experiences a decrease in volume until reaching a constant volume. Meanwhile, samples with loose sand $(\mathrm{Dr}=10 \%)$ have a contractionary behaviour, where the sample volume decreases with increasing shear stresses up to a value of constant volume when the shear stress reaches the maximum value. The dense sand samples reached higher values of peak shear stress in comparison with the loose sand 
Table 4 Summary of direct shear test results for peak shear stress

\begin{tabular}{|c|c|c|c|c|c|c|c|c|}
\hline \multicolumn{3}{|c|}{ Reinforced soil sample } & \multicolumn{2}{|c|}{ Circular box $D=63 \mathrm{~mm}$} & \multicolumn{2}{|c|}{ Square box $L=100 \mathrm{~mm}$} & \multicolumn{2}{|c|}{ Difference between two types of box } \\
\hline Soil type & $\begin{array}{l}\text { Relative } \\
\text { density (\%) }\end{array}$ & $\begin{array}{l}\text { Reinforcement } \\
\text { type }\end{array}$ & $\begin{array}{l}\text { Cohesion } \\
(\mathrm{kPa})\end{array}$ & $\begin{array}{l}\text { Friction } \\
\text { angle }\left({ }^{\circ}\right)\end{array}$ & $\begin{array}{l}\text { Cohesion } \\
(\mathrm{kPa})\end{array}$ & $\begin{array}{l}\text { Friction } \\
\text { angle }\left({ }^{\circ}\right)\end{array}$ & $\begin{array}{l}\text { Cohesion } \\
(\%)\end{array}$ & $\begin{array}{l}\text { Friction } \\
\text { angle }(\%)\end{array}$ \\
\hline \multirow[t]{5}{*}{ SW } & \multirow[t]{5}{*}{10} & Without & 0.0 & 50.9 & 7.2 & 50.1 & - & 1.6 \\
\hline & & Uniaxial & 7.9 & 51.9 & 12.7 & 51.5 & 60.8 & 0.8 \\
\hline & & Biaxial & 2.4 & 51.7 & 7.2 & 51.3 & 200 & 0.8 \\
\hline & & Woven & 11.2 & 51.8 & 12.8 & 51.9 & 14.3 & 0.2 \\
\hline & & Nonwoven & 13.9 & 51.9 & 15.7 & 51.9 & 12.9 & - \\
\hline \multirow[t]{5}{*}{ SW } & \multirow[t]{5}{*}{90} & Without & 11.1 & 59.2 & 31.0 & 58.6 & 179.3 & 1.0 \\
\hline & & Uniaxial & 11.0 & 64.9 & 37.8 & 63.8 & 243.6 & 1.7 \\
\hline & & Biaxial & 24.1 & 63.1 & 44.5 & 62.3 & 84.6 & 1.3 \\
\hline & & Woven & 26.0 & 64.1 & 33.8 & 64.0 & 30.0 & 0.2 \\
\hline & & Nonwoven & 37.9 & 63.4 & 51.9 & 62.6 & 36.9 & 1.3 \\
\hline \multirow[t]{5}{*}{ SM } & \multirow[t]{5}{*}{10} & Without & 0.0 & 42.5 & 0.7 & 42.3 & - & 0.5 \\
\hline & & Uniaxial & 9.3 & 48.5 & 9.3 & 48.2 & 0.0 & 0.6 \\
\hline & & Biaxial & -0.5 & 49.7 & 0.9 & 49.7 & 280 & 0.0 \\
\hline & & Woven & 11.4 & 50.1 & 14.1 & 50.4 & 23.7 & 0.6 \\
\hline & & Nonwoven & 5.0 & 48.9 & 3.1 & 50.5 & 61.3 & 3.3 \\
\hline \multirow[t]{5}{*}{ SM } & \multirow[t]{5}{*}{90} & Without & 20.1 & 58.1 & 33.2 & 57.8 & 65.2 & 0.5 \\
\hline & & Uniaxial & 18.3 & 63.8 & 39.2 & 63.3 & 114.2 & 0.8 \\
\hline & & Biaxial & 25.3 & 64.7 & 38.3 & 64.7 & 51.4 & 0.0 \\
\hline & & Woven & 49.8 & 63.4 & 55.6 & 63.3 & 11.6 & 0.2 \\
\hline & & Nonwoven & 55.5 & 63.4 & 65.7 & 61.6 & 18.4 & 2.9 \\
\hline
\end{tabular}

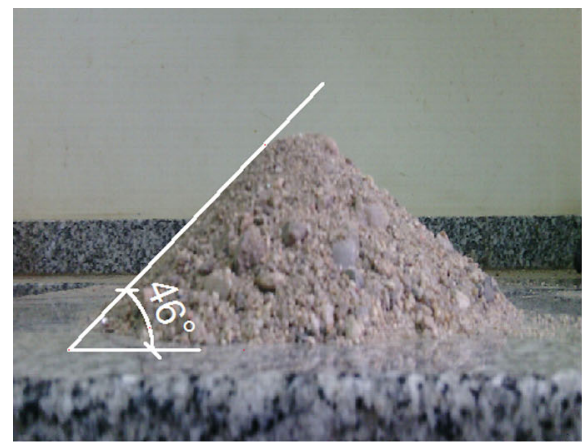

(a) Well graded sand (SW)

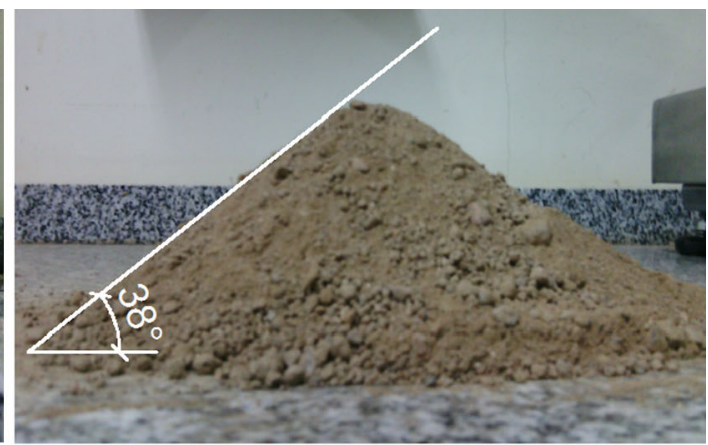

(b) Silty sand (SM)

Fig. 11 Angle of repose

samples. In Table 4 can be seen that the friction angles are greater for dense sands, which are similar with the results obtained by Tuna and Altun [10]. Also, the apparent cohesion achieved was higher in the dense samples in comparison with loose samples (see Table 4).

\section{Sample Size}

Both boxes considered in the study have difference in shape, however, for qualitative comparison purpose the results are shown in the same graph. Figure $9 a$ and $b$ showed higher peak shear stress values for most of the samples tested in the larger shear box (square box, $L=100 \mathrm{~mm}$ ) compared to the samples tested in the smaller shear box (circular box, diameter $D=63 \mathrm{~mm}$ ). The failure envelopes for samples in square box are drawn above the failure envelopes of the samples in circular box (see Fig. 10), which shows higher stress values for samples in larger shear box. However, although shear stresses are higher in the larger box (square box), the friction parameters are more favorable for the samples tested in the smaller box (circular box). Also, the peak friction angles 
Table 5 Summary of direct shear test results for residual shear stress

\begin{tabular}{|c|c|c|c|c|c|c|c|c|}
\hline \multicolumn{3}{|c|}{ Reinforced soil sample } & \multicolumn{2}{|c|}{ Circular box $D=63 \mathrm{~mm}$} & \multicolumn{2}{|c|}{ Square box $L=100 \mathrm{~mm}$} & \multicolumn{2}{|c|}{ Difference between two types of box } \\
\hline Soil type & $\begin{array}{l}\text { Relative } \\
\text { density }(\%)\end{array}$ & $\begin{array}{l}\text { Reinforcement } \\
\text { type }\end{array}$ & $\begin{array}{l}\text { Cohesion } \\
(\mathrm{kPa})\end{array}$ & $\begin{array}{l}\text { Friction } \\
\text { angle }\left(^{\circ}\right)\end{array}$ & $\begin{array}{l}\text { Cohesion } \\
(\mathrm{kPa})\end{array}$ & $\begin{array}{l}\text { Friction } \\
\text { angle }\left({ }^{\circ}\right)\end{array}$ & Cohesion $(\%)$ & $\begin{array}{l}\text { Friction angle } \\
(\%)\end{array}$ \\
\hline \multirow[t]{5}{*}{ SW } & \multirow[t]{5}{*}{90} & Without & 0.1 & 49.1 & 0.3 & 49.0 & 200 & 0.2 \\
\hline & & Uniaxial & -1.6 & 60.4 & 2.3 & 60.3 & 243.8 & 0.2 \\
\hline & & Biaxial & -4.1 & 59.1 & 5.9 & 58.2 & 243.9 & 1.5 \\
\hline & & Woven & -0.4 & 60.5 & 0.5 & 60.5 & 225 & 0.0 \\
\hline & & Nonwoven & 1.4 & 58.6 & 5.2 & 58.2 & 271.4 & 0.7 \\
\hline \multirow[t]{5}{*}{ SW } & \multirow[t]{5}{*}{90} & Without & 14.2 & 49.9 & 9.8 & 50.1 & 44.9 & 0.4 \\
\hline & & Uniaxial & 9.4 & 55.6 & 8.3 & 55.3 & 13.3 & 0.5 \\
\hline & & Biaxial & 13.1 & 56.2 & 17.7 & 55.8 & 35.1 & 0.7 \\
\hline & & Woven & 28.9 & 54.8 & 45.1 & 54.7 & 56.1 & 0.2 \\
\hline & & Nonwoven & 35.1 & 54.7 & 41.2 & 54.3 & 17.4 & 0.7 \\
\hline
\end{tabular}

Table 6 Shear strength improvement $\left(C_{\mathrm{i}}\right)$ for peak shear stress

\begin{tabular}{|c|c|c|c|c|c|c|c|c|c|c|}
\hline \multicolumn{2}{|c|}{ Reinforced soil sample } & \multirow{2}{*}{\multicolumn{3}{|c|}{$\frac{\text { Circular box } D=63 \mathrm{~mm}}{\text { Vertical stress, } \sigma_{\mathrm{v}}(\mathrm{kPa})}$}} & \multirow{2}{*}{\multicolumn{3}{|c|}{$\frac{\text { Square box } L=100 \mathrm{~mm}}{\text { Vertical stress, } \sigma_{\mathrm{v}}(\mathrm{kPa})}$}} & \multirow{2}{*}{\multicolumn{3}{|c|}{$\frac{\text { Difference between two types of box }(\%)}{\text { Vertical stress, } \sigma_{\mathrm{v}}(\mathrm{kPa})}$}} \\
\hline \multirow[t]{2}{*}{ Soil type $(D r)$} & \multirow{2}{*}{$\begin{array}{l}\text { Geosynthetic } \\
\text { type }\end{array}$} & & & & & & & & & \\
\hline & & 15.7 & 31.4 & 62.8 & 15.7 & 31.4 & 62.8 & 15.7 & 31.4 & 62.8 \\
\hline \multirow[t]{4}{*}{ SW (10 \%) } & Uniaxial & 1.44 & 1.24 & 1.14 & 1.25 & 1.17 & 1.11 & 15.2 & 6.0 & 2.7 \\
\hline & Biaxial & 1.15 & 1.09 & 1.06 & 1.03 & 1.03 & 1.04 & 11.7 & 5.8 & 1.9 \\
\hline & Woven & 1.61 & 1.32 & 1.18 & 1.26 & 1.18 & 1.13 & 27.8 & 11.9 & 4.4 \\
\hline & Nonwoven & 1.75 & 1.40 & 1.22 & 1.37 & 1.24 & 1.16 & 27.7 & 12.9 & 5.2 \\
\hline \multirow[t]{4}{*}{ SW (90 \%) } & Uniaxial & 1.19 & 1.23 & 1.25 & 1.23 & 1.23 & 1.23 & 3.4 & 0.0 & 1.6 \\
\hline & Biaxial & 1.47 & 1.35 & 1.27 & 1.31 & 1.27 & 1.23 & 12.2 & 6.3 & 3.3 \\
\hline & Woven & 1.56 & 1.43 & 1.34 & 1.16 & 1.19 & 1.21 & 34.5 & 20.2 & 10.7 \\
\hline & Nonwoven & 1.85 & 1.58 & 1.41 & 1.45 & 1.37 & 1.29 & 27.6 & 15.3 & 9.3 \\
\hline \multirow[t]{4}{*}{ SM (10 \%) } & Uniaxial & 1.88 & 1.56 & 1.39 & 1.80 & 1.52 & 1.38 & 4.4 & 2.6 & 0.7 \\
\hline & Biaxial & 1.26 & 1.27 & 1.28 & 1.63 & 1.46 & 1.38 & 29.4 & 15.0 & 7.8 \\
\hline & Woven & 2.10 & 1.70 & 1.50 & 2.21 & 1.78 & 1.55 & 5.2 & 4.7 & 3.3 \\
\hline & Nonwoven & 1.60 & 1.43 & 1.34 & 1.48 & 1.41 & 1.37 & 8.1 & 1.4 & 2.2 \\
\hline \multirow[t]{4}{*}{ SM (90 \%) } & Uniaxial & 1.11 & 1.16 & 1.21 & 1.21 & 1.22 & 1.23 & 9.0 & 5.2 & 1.7 \\
\hline & Biaxial & 1.29 & 1.30 & 1.31 & 1.23 & 1.26 & 1.29 & 4.9 & 3.2 & 1.6 \\
\hline & Woven & 1.79 & 1.60 & 1.45 & 1.49 & 1.42 & 1.36 & 20.1 & 12.7 & 6.6 \\
\hline & Nonwoven & 1.92 & 1.68 & 1.50 & 1.63 & 1.49 & 1.37 & 17.8 & 12.8 & 9.5 \\
\hline
\end{tabular}

for samples in the square box are less than the peak friction angles for samples in the circular box, the biggest difference between values of peak friction angle for the two types of shear box was $3.3 \%$ and presented in silty sand (SM) dense, reinforced with nonwoven geotextile (see Table 4). In contrast to peak friction angles, residual friction angles were slightly higher for the samples in circular box. The maximum difference between values of residual friction angle for the two types of box was $1.5 \%$ for samples of well graded sand (SW) reinforced with biaxial geogrid (see Table 5). As shown in Table 4, the values of apparent cohesion for peak shear stress are greater in square shear box, the maximum difference in the apparent cohesion between the two types of shear box was $26.8 \mathrm{kPa}$, and this value was reached to the well graded sand (SW) dense, reinforced with uniaxial geogrid. For residual stresses, the apparent cohesion was also higher in square box, the biggest difference in the values of apparent cohesion between the two types of box was $23.8 \mathrm{kPa}$ for samples of well graded sand (SW) reinforced with 
Table 7 Shear strength improvement $\left(C_{\mathrm{i}}\right)$ for residual shear stress

\begin{tabular}{|c|c|c|c|c|c|c|c|c|c|c|}
\hline \multicolumn{2}{|c|}{ Reinforced soil sample } & \multirow{2}{*}{\multicolumn{3}{|c|}{$\frac{\text { Circular box } D=63 \mathrm{~mm}}{\text { Vertical stress, } \sigma_{\mathrm{v}}(\mathrm{kPa})}$}} & \multirow{2}{*}{\multicolumn{3}{|c|}{$\frac{\text { Square box } L=100 \mathrm{~mm}}{\text { Vertical stress, } \sigma_{\mathrm{v}}(\mathrm{kPa})}$}} & \multirow{2}{*}{\multicolumn{3}{|c|}{$\frac{\text { Difference between two types of box }(\%)}{\text { Vertical stress, } \sigma_{\mathrm{v}}(\mathrm{kPa})}$}} \\
\hline \multirow[t]{2}{*}{ Soil type (Dr) } & \multirow{2}{*}{$\begin{array}{l}\text { Geosynthetic } \\
\text { type }\end{array}$} & & & & & & & & & \\
\hline & & 15.7 & 31.4 & 62.8 & 15.7 & 31.4 & 62.8 & 15.7 & 31.4 & 62.8 \\
\hline \multirow[t]{4}{*}{ SW (90 \%) } & Uniaxial & 1.44 & 1.48 & 1.50 & 1.11 & 1.27 & 1.38 & 29.7 & 16.5 & 8.7 \\
\hline & Biaxial & 1.22 & 1.33 & 1.39 & 1.16 & 1.26 & 1.32 & 5.2 & 5.6 & 5.3 \\
\hline & Woven & 1.51 & 1.52 & 1.53 & 1.32 & 1.41 & 1.46 & 14.4 & 7.8 & 4.8 \\
\hline & Nonwoven & 1.50 & 1.46 & 1.44 & 1.88 & 1.69 & 1.56 & 25.3 & 15.8 & 8.3 \\
\hline \multirow[t]{4}{*}{ SM $(90 \%)$} & Uniaxial & 0.99 & 1.07 & 1.14 & 1.08 & 1.13 & 1.16 & 9.1 & 5.6 & 1.8 \\
\hline & Biaxial & 1.11 & 1.17 & 1.21 & 1.43 & 1.35 & 1.30 & 28.8 & 15.4 & 7.4 \\
\hline & Woven & 1.56 & 1.43 & 1.33 & 2.35 & 1.89 & 1.57 & 50.6 & 32.2 & 18.0 \\
\hline & Nonwoven & 1.74 & 1.54 & 1.39 & 2.21 & 1.79 & 1.51 & 27.0 & 16.2 & 8.6 \\
\hline
\end{tabular}

Table 8 Values of $\delta / \phi$ for peak shear stress

\begin{tabular}{|c|c|c|c|c|c|c|c|c|c|c|}
\hline \multicolumn{2}{|c|}{ Reinforced soil sample } & \multirow{2}{*}{\multicolumn{3}{|c|}{$\frac{\text { Circular box } D=63 \mathrm{~mm}}{\text { Vertical stress, } \sigma_{\mathrm{v}}(\mathrm{kPa})}$}} & \multirow{2}{*}{\multicolumn{3}{|c|}{$\frac{\text { Square box } L=100 \mathrm{~mm}}{\text { Vertical stress, } \sigma_{\mathrm{v}}(\mathrm{kPa})}$}} & \multirow{2}{*}{\multicolumn{3}{|c|}{$\frac{\text { Difference between two types of box }(\%)}{\text { Vertical stress, } \sigma_{\mathrm{v}}(\mathrm{kPa})}$}} \\
\hline \multirow[t]{2}{*}{ Soil type $(D r)$} & \multirow{2}{*}{$\begin{array}{l}\text { Geosynthetic } \\
\text { type }\end{array}$} & & & & & & & & & \\
\hline & & 15.7 & 31.4 & 62.8 & 15.7 & 31.4 & 62.8 & 15.7 & 31.4 & 62.8 \\
\hline \multirow[t]{4}{*}{ SW (10\%) } & Uniaxial & 1.61 & 1.62 & 1.37 & 1.73 & 1.62 & 1.60 & 7.5 & 0.0 & 16.8 \\
\hline & Biaxial & 0.60 & 1.01 & 0.42 & 0.76 & 0.96 & 0.83 & 26.7 & 5.2 & 97.6 \\
\hline & Woven & 1.23 & 1.17 & 0.64 & 1.42 & 1.17 & 0.96 & 15.4 & 0.0 & 50.0 \\
\hline & Nonwoven & 1.36 & 1.28 & 0.81 & 1.50 & 1.42 & 1.10 & 10.3 & 10.9 & 35.8 \\
\hline \multirow[t]{4}{*}{ SW (90 \%) } & Uniaxial & 1.42 & 1.44 & 1.43 & 1.49 & 1.51 & 1.49 & 4.9 & 4.9 & 4.2 \\
\hline & Biaxial & 1.43 & 1.38 & 1.32 & 1.49 & 1.48 & 1.44 & 4.2 & 7.2 & 9.1 \\
\hline & Woven & 1.29 & 1.31 & 1.13 & 0.68 & 1.42 & 1.27 & 89.7 & 8.4 & 12.4 \\
\hline & Nonwoven & 1.35 & 1.38 & 1.18 & 1.46 & 1.43 & 1.37 & 8.1 & 3.6 & 16.1 \\
\hline \multirow[t]{4}{*}{ SM (10\%) } & Uniaxial & 1.99 & 1.96 & 1.85 & 2.02 & 2.06 & 1.97 & 1.5 & 5.1 & 6.5 \\
\hline & Biaxial & 1.51 & 1.07 & 1.37 & 1.86 & 1.95 & 1.81 & 23.2 & 82.2 & 32.1 \\
\hline & Woven & 1.58 & 1.42 & 1.15 & 1.85 & 1.85 & 1.62 & 17.1 & 30.3 & 40.9 \\
\hline & Nonwoven & 1.33 & 0.97 & 0.90 & 1.55 & 1.54 & 1.43 & 16.5 & 58.8 & 58.9 \\
\hline \multirow[t]{4}{*}{ SM (90\%) } & Uniaxial & 1.44 & 1.40 & 1.44 & 1.53 & 1.52 & 1.51 & 6.3 & 8.6 & 4.9 \\
\hline & Biaxial & 1.42 & 1.40 & 1.37 & 1.50 & 1.48 & 1.48 & 5.6 & 5.7 & 8.0 \\
\hline & Woven & 1.44 & 1.36 & 1.27 & 1.50 & 1.44 & 1.41 & 4.2 & 5.9 & 11.0 \\
\hline & Nonwoven & 1.45 & 1.40 & 1.29 & 1.50 & 1.48 & 1.41 & 3.4 & 5.7 & 9.3 \\
\hline
\end{tabular}

nonwoven geotextile (see Table 5). Shear strength improvement (Tables 6 and 7) shows a maximum difference of $29.4 \%$ between both shear boxes.

\section{Type of Geosynthetics}

Reinforced soil samples have higher shear stresses relative to samples without reinforcement. The maximum values of peak and residual shear stress were 180.91 and $133.42 \mathrm{kPa}$, these values are presented for samples of silty sand (SM) dense, reinforced with woven geotextile in square shear box. Based on the data failure envelopes presented in Fig. 10, can be seen that the samples reinforced with nonwoven geotextile showed failure envelopes with shear stresses higher except for samples of silty sand (SM) loose, where the failure envelope with higher shear stresses was achieved for samples with woven geotextile. Similar results were presented for the apparent cohesion (see Table 4), the samples with nonwoven geotextile reached higher values for apparent cohesion, except in the samples of silty sand 
Table 9 Values of $\delta / \phi$ for residual shear stress

\begin{tabular}{|c|c|c|c|c|c|c|c|c|c|c|}
\hline \multicolumn{2}{|c|}{ Reinforced soil sample } & \multirow{2}{*}{\multicolumn{3}{|c|}{$\frac{\text { Circular box } D=63 \mathrm{~mm}}{\text { Vertical stress, } \sigma_{\mathrm{v}}(\mathrm{kPa})}$}} & \multirow{2}{*}{\multicolumn{3}{|c|}{$\frac{\text { Square box } L=100 \mathrm{~mm}}{\text { Vertical stress, } \sigma_{\mathrm{v}}(\mathrm{kPa})}$}} & \multirow{2}{*}{\multicolumn{3}{|c|}{$\frac{\text { Difference between two types of box }(\%)}{\text { Vertical stress, } \sigma_{\mathrm{v}}(\mathrm{kPa})}$}} \\
\hline \multirow[t]{2}{*}{ Soil type $(D r)$} & \multirow{2}{*}{$\begin{array}{l}\text { Geosynthetic } \\
\text { type }\end{array}$} & & & & & & & & & \\
\hline & & 15.7 & 31.4 & 62.8 & 15.7 & 31.4 & 62.8 & 15.7 & 31.4 & 62.8 \\
\hline \multirow[t]{4}{*}{ SW (90 \%) } & Uniaxial & 1.35 & 1.43 & 1.33 & 1.35 & 1.38 & 1.44 & 0.0 & 3.5 & 8.3 \\
\hline & Biaxial & 1.12 & 1.27 & 1.01 & 1.21 & 1.22 & 1.30 & 8.0 & 3.9 & 28.7 \\
\hline & Woven & 0.87 & 1.05 & 0.73 & 0.92 & 1.11 & 1.11 & 5.7 & 5.7 & 52.1 \\
\hline & Nonwoven & 0.97 & 0.98 & 0.68 & 1.27 & 1.15 & 1.17 & 30.9 & 17.3 & 72.1 \\
\hline \multirow[t]{4}{*}{ SW (90 \%) } & Uniaxial & - & 0.82 & 1.17 & - & 1.37 & 1.33 & - & 67.1 & 13.7 \\
\hline & Biaxial & 0.83 & 0.87 & 0.93 & 1.35 & 1.29 & 1.28 & 62.7 & 48.3 & 37.6 \\
\hline & Woven & 0.89 & 0.78 & 0.70 & 1.29 & 1.22 & 1.14 & 44.9 & 56.4 & 62.9 \\
\hline & Nonwoven & 0.94 & 0.89 & 0.75 & 1.27 & 1.21 & 1.11 & 35.1 & 36.0 & 48.0 \\
\hline
\end{tabular}

(SM) loose, where apparent cohesion was greater for samples with woven geotextile. However, although the samples reinforced with geotextile are showed higher values of shear stresses, the higher friction angles of reinforced soil were achieved for the samples reinforced with geogrids, as seen in Tables 4 and 5. This occurs because the failure envelopes of these samples had higher slopes compared to the other samples. For the samples of well graded sand (SW) dense, the best and worst shear strength improvement occurs for samples reinforced with uniaxial and biaxial geogrid respectively. For samples of silty sand (SM), maximum shear strength improvement occurs for samples reinforced with biaxial geogrid in loose and dense sand. The values of peak and residual apparent friction angle in the normalized form, $\delta / \phi$, showed the optimum behaviour for samples reinforced with geogrid for both types of soil used in the tests (see Tables 8 and 9). The behavior of reinforced soil composite obtained from this study is mainly pertinent to geosynthetic properties presented in Table 2 so additional testing is required to present a complete comparison of geotextile-soil and geogrid-soil composite.

\section{Conclusions}

This paper presents the results of direct shear tests program, carried out in order to establish the effect of some factors on the frictional behaviour of geosynthetic reinforced soil composite. The variables considered in the tests were: two types of granular soil, samples with two relative densities, two types of shear box and 4 types of geosynthetic included. From the study, the follow conclusions can be drawn:

1. Peak friction angles of reinforced soil for samples of loose sand increased between 0.8 and $8.2^{\circ}$ depending on the type of geosynthetic employee; Apparent cohesion presented in reinforced soil was higher for the samples reinforced with geotextile, which reached maximum values of cohesion of $65.7 \mathrm{kPa}$ for samples reinforced with nonwoven geotextile in dense soil.

2. Sample size had no significant effect on the shear parameters of geosynthetic reinforced soil composite, the friction angle of reinforced soil presented similar values in the two types of shear box and apparent cohesion was slightly higher for samples prepared in shear square box of $100 \times 100 \mathrm{~mm}^{2}$. The maximum difference in the apparent cohesion between the two types of shear box was $23.6 \mathrm{kPa}$, which is a value of cohesion that does not have much influence on the shear strength of the soil. Tests may be conducted using a large shear box to verify the sample size effect.

3. The improvement achieved in the shear strength by including a geosynthetic layer in the soil mass was greater in samples reinforced with geogrid, the maximum values of shear strength improvement, $C_{\mathrm{i}}$, were 2.21. The improvement achieved in dense samples was similar to peak and residual stresses. The behavior of geosynthetic reinforced soil composite depends on specific properties of geosynthetic and soil, these findings cannot be generalized and need to be verified for other types of geosynthetic-soil composite.

4. The interaction at the geosynthetic-soil interface can be represented by an apparent friction angle $\delta$, and this value is determined from experimental investigation. Evaluation of the apparent interface friction angle in the normalized form $\delta / \phi$ (maximum and mobilized values), are found from the range from 2.06 to 0.42 and this ratio reached minimum values for high vertical stress. The maximum values of $\delta / \phi$ are presented for dense samples reinforced with uniaxial geogrid. 
Acknowledgments The authors would like to thanks the National Scientific and Technical Research Council (CONICET), the National Technological University (UTN), the Regional Faculty of Córdoba (UTN-FRC, Argentina) and CORIPA S.A. by samples of geosynthetic supplied.

\section{References}

1. Palmeira EM (2008) Soil-geosynthetic interaction: modeling and analysis. Geotext Geomembr 27(5):368-390

2. Takasumi DL, Green KR, Holtz R (1991) Soil-geosynthetics interface strength characteristics: a review of state-of the-art testing procedures. In: proceedings of the geosynthetics'91 conference, Atlanta 1:87-100

3. Tan SA, Chew SH, Wong WK (1998) Sand-geotextile interface shear strength by torsional ring shear tests. Geotext Geomembr 16(3):299-328

4. Cerato AB, Lutenegger AJ (2006) Specimen size and scale effects of direct shear box tests of sands. Geotech Test J 29(6):1-10. doi:10.1520/GTJ100312

5. Abu-Farsakh MY, Coronel J, Tao M (2007) Effect of soil moisture content and dry density on cohesive soil-geosynthetic interactions using large direct shear tests. J Mater Civ Eng 19(7):540-549

6. Liu CN, Ho YH, Huang JW (2009) Large scale direct shear tests of soil/PET-yarn geogrid interfaces. Geotext Geomembr 27:19-30

7. Lopes ML, Silvano R (2010) Soil/geotextile interface behaviour in direct shear and pullout movements. Geotech Geol Eng 28:791-804

8. Hossain B, Hossain Z, Sakai T (2012) Interaction properties of geosynthetic with different backfill soils. Int $\mathbf{J}$ Geosci 3:1033-1039. doi:10.4236/ijg.2012.35104

9. Anubhav Basudhar PK (2013) Interface behaviour of woven geotextile with rounded and angular particle sand. J Mater Civ Eng ASCE 25(12):1970-1974

10. Tuna SC, Altun S (2012) Mechanical behaviour of sand-geotextile interface. Sci Iran 19(4):1044-1051

11. Vieira CS, Lopes ML (2013) Soil-geosynthetic interface shear strength by simple and direct shear tests. In: Proceedings of the 18th international conference on soil mechanics and geotechnical engineering, Paris 1:3497-3500

12. Kim D, Ha S (2014) Effects of particle size on the shear behaviour of coarse grained soils reinforced with geogrid. Mater 7:963-979. doi:10.3390/ma7020963
13. Vangla P, Latha GM (2015) Influence of particle size on the friction and interfacial shear strength of sands of similar morphology. Int J Geosynth Ground Eng 1(6):1-12. doi:10.1007/ s40891-014-0008-9

14. Choudhary AQ, Krishna AM (2016) Experimental investigation of interface behaviour of different types of granular soil/geosynthetics. Int J Geosynth Ground Eng 2(1):1-11. doi:10. 1007/s40891-016-0044-8

15. Jewell RA, Wroth CP (1987) Direct shear tests and reinforced sand. Géotech 37(1):53-68

16. Athanasopoulos GA (1993) Effect of particle size on the mechanical behaviour of sand-geotextile composites. Geotext Geomembr 12(3):255-273

17. Bauer GE, Zhao Y (1994) A realistic stress transfer model for geogrids in pullout. In: Proceedings of the 5th International Conference on Geotextiles, Geomembranes and Related Products, vol 1. Singapore, pp 457-460

18. Palmeira EM (1999) Execution and interpretation of laboratory tests on geosynthetic material (in Portuguese). In: Proceedings of the 1st south-American symposium on geosynthetics, ABMSISSMGE, vol 1. Rio de Janeiro, pp 87-108

19. Moayedi H, Huat BBK, Kazemian S, Asadi A (2010) Optimization of tension absorption of geosynthetics through reinforced slope. Electron J Geotech Eng 15(2):93-104. Available at the website ejge.com at http://www.ejge.com/2010/Ppr10.010/ Ppr10.010.pdf

20. Sayão ASFJ, Sieira ACCF (2012) Evaluation of direct shear tests on geogrid reinforced soil. Soils Rocks 35(1):65-74

21. ASTM D 5321 (2008) Standard test method for determining the coefficient of soil and geosynthetic or geosynthetic and geosynthetic friction by direct shear method. ASTM Designation: ASTMD5321.08, ASTM

22. Jones CJFP (1996) Earth reinforcement and soil structures. Thomas Telford, New York

23. Koerner RM (1998) Designing with geosynthetics, 4th edn. Prentice Hall, New Jersey

24. Holtz RD, Kovacs WD (1981) An introduction to geotechnical engineering. Prentice-Hall, Englewood Cliffs, NJ

25. Chik Z, Vallejo LE (2005) Characterization of the angle of repose of binary granular materials. Can Geotech J 42:683-692

26. ASTM C1444-00 (2001) Standard method for measuring the angle of repose of free-flowing mold powders. ASTM Designation: ASTM C1444-00.01, ASTM

27. Hataf N, Rahimi MM (2006) Experimental investigation of bearing capacity of sand reinforced with randomly distributed tire shreds. Constr Build Mater 20:910-916 